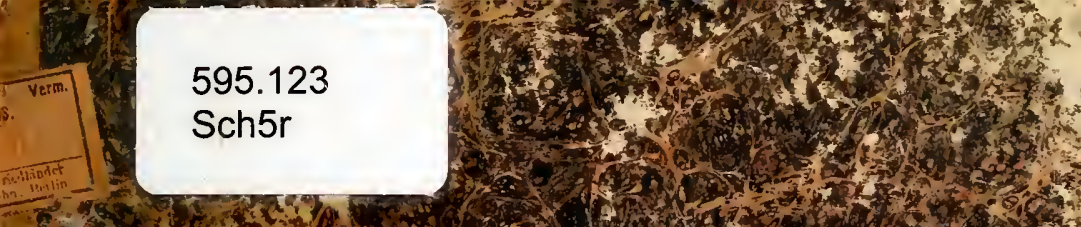

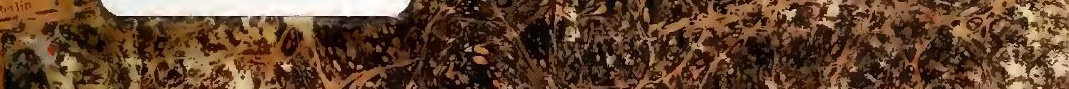

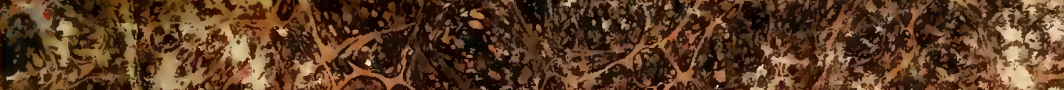

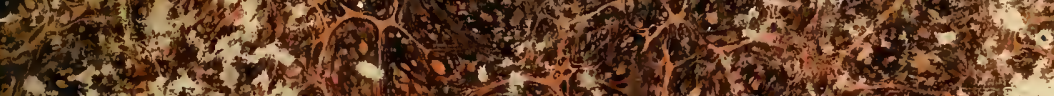

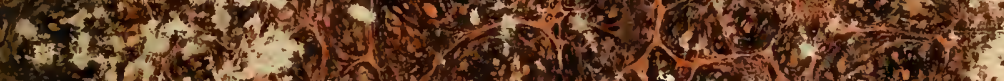

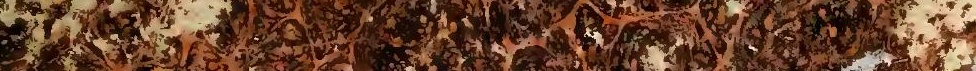

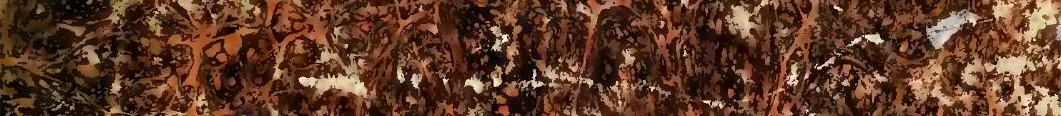

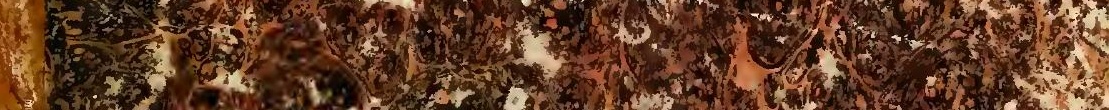
(4)

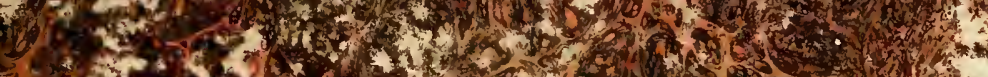

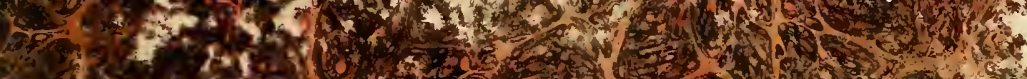

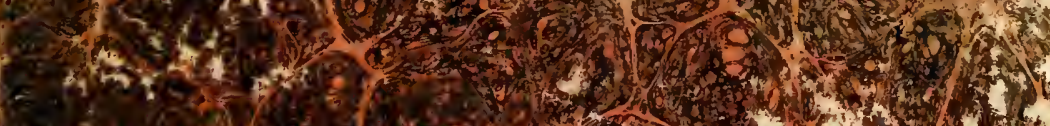

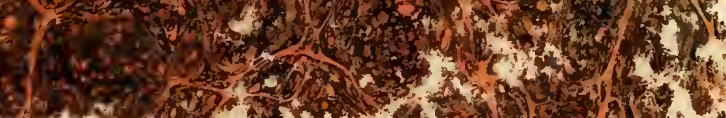

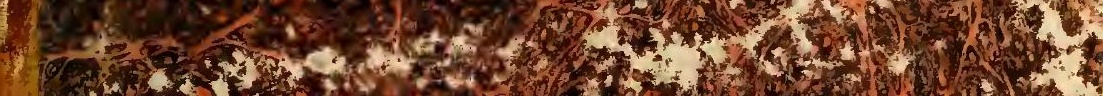

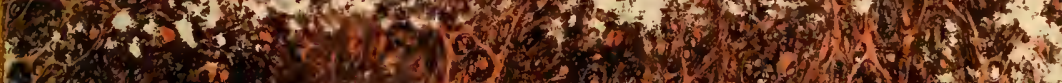

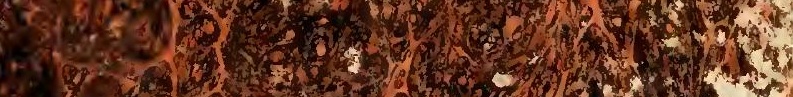

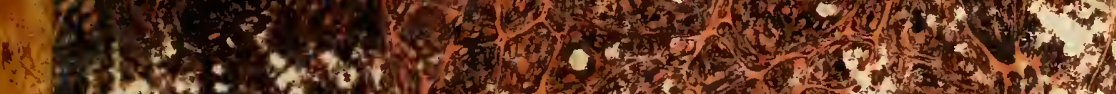

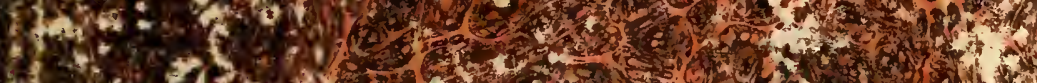

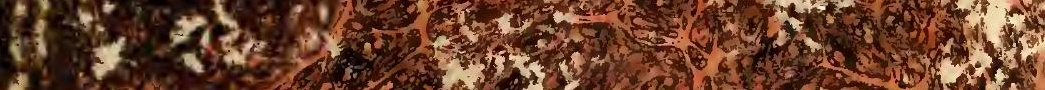
2.

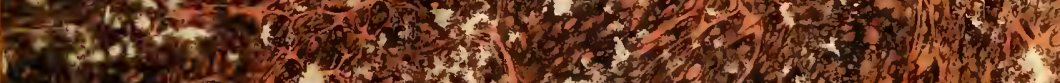

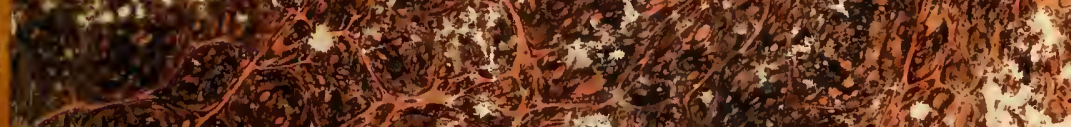

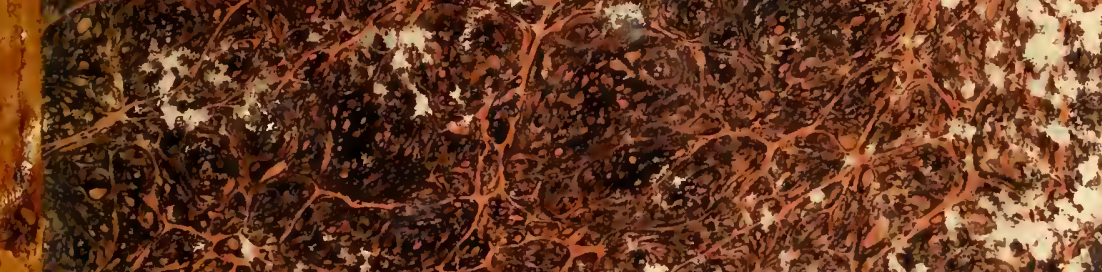

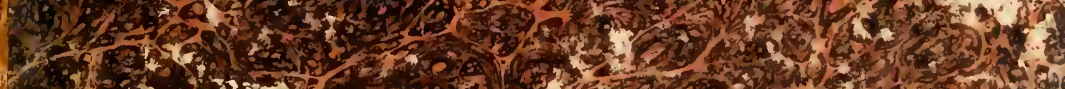
(2)

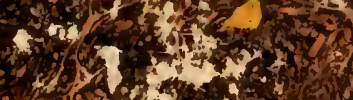

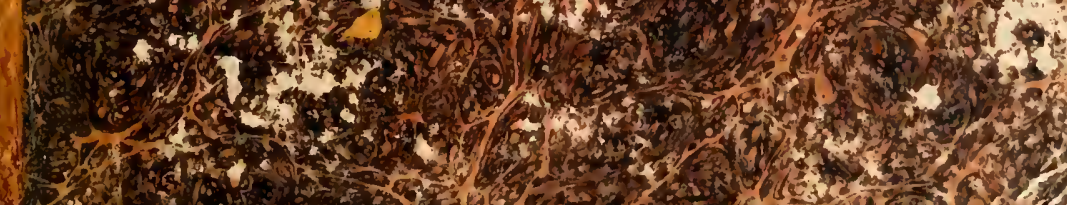



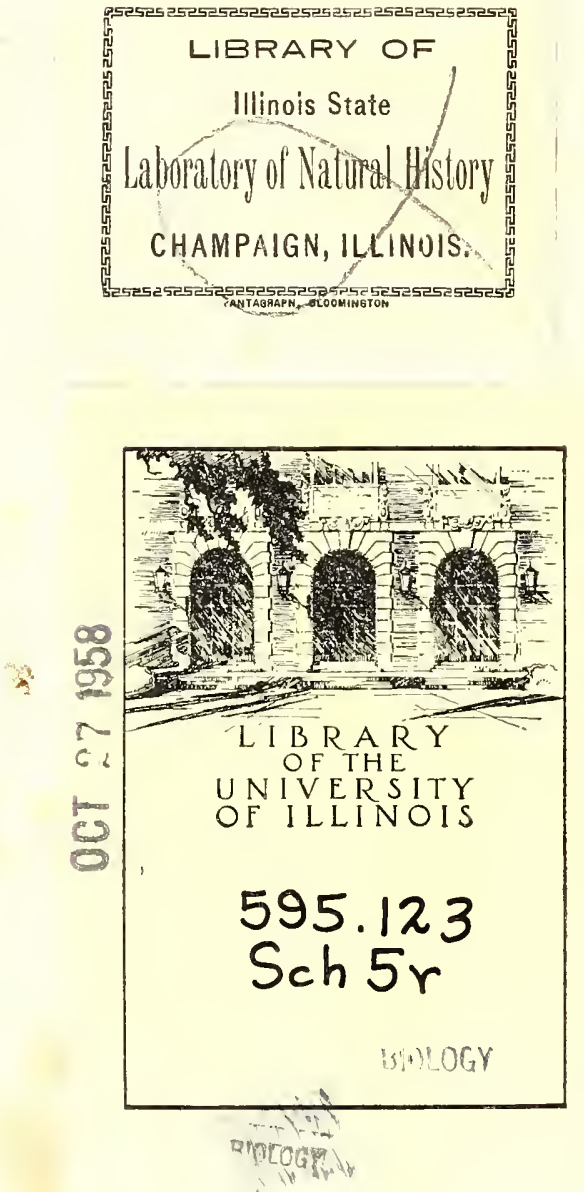


Digitized by the Internet Archive in 2011 with funding from University of Illinois Urbana-Champaign 



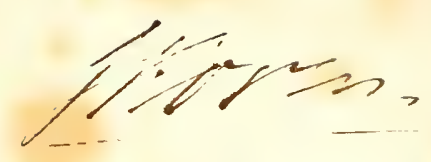

Die

\section{rhabdocoelen Strudelwürmer}

(Turbellaria rhabdocoela)

des süssen Wassers.

Besclirieben und abgebildet

ron

Eruard Oscar Selsmidt, Dr.,

Privatdocenteu an der Universitat zu Jena.

$\boldsymbol{J} \mathbf{e} \mathbf{a}$,

Druck und Verlag von Friedrich Mauke.

1848. 



\section{墨 i n l e i t ung.}

Ws wird wohl selbst den jüngeren der heutigen Naturforscher nicht vergönnt sein, jenen Bau aufgefülurt zu sehen, zu dem jetzt von allen Seiten Material und Steine herbeigetragen werden; erst künftigen Geschlechtern ist die Verwirklichung einer allgemeinen vergleichenden Physiologie vorbelalten. Und so sind die dankenswerthesten Arbeiten für uns nicht in der Zusammenfassung von Resultaten zu suchen, weil der verbindenden Fäden noch zu wenige sind, sondern man muss sich vor der Hand durch specielle Untersuchungen nützlich machen, bei denen man aber das Allgemeine und die Vergleichung nicht aus den Augen verlieren darf.

An Arbeiten der Art, wie die vorliegende, muss man vor Allem zwei Anforderungen stellen. Einmal ist mit einer zoologischen Monographie gar nichts geleistet, welche rein zoologisch ist, in alten Sinne des Wortes, d. h. einigge Dutzend Species nothdürftig systematisirt und beschreibt, von der Beleuchtung der anatomischen und physiologischen Verhältnisse so viel als möglich abstehend. Lässt sie sich dann aber dieser höheren Rücksichten angrelegen sein, so 
ist ein nothwendiges Kriterium fiir die Güte des Gegebenen, dass der letyte Untersucher mehr und deutlicher gesehen hat, als seine Vorgänger. ,Ls ist nichts gemeiner als Augen halien, und nichts seltener als seben zal können," sagt O. F. Mïller. Darum ist es auch so sehr leicht, weniger zu sehen, als andere Leute. In der Weise, hoffe ich, habe ich es mir nicht leicht gemacht, wovon man sich durch einen Blick in das Buch von Oersted iber die Plattwürmer (Copenhagen 1844), so viel ich weiss das letzte, welches sich in Allgencinen und Speciellen über die Rhabdocoelen verbreitet lrat, iiberzengen mag. Die neuen Species, die sich mir dargeboten, sind auch kein zn rerachtender Ballast, indem sich zum Theil aus itnen interessante $\Lambda$ ufschlüsse iiber die ganze Gruppe ergeben. Sich nach den Abbildungen von Ocrsted zu orientiren, ist nicht recht möglich; zum grössten Theil vergeblich ist die Mülse, nach Dujés's Zeiclinungen, wie sie in Froriep's Notizen (BJ. 23. 1829) mitgetheilt sind, die Arten bestimmen zn wollen. Dem hofe ich durch meine Tafeln, so weit sie reichen, etwas abzuhelfen. Jener Mangelhaftigkeit aber der Hülfsmittel für die Bestimmung wird es zuzuschreiben sein, wenn ich vielleicht ein und das andere Thier als neu beschreibe, welches schon früher entdeckt war'; auch habe ich die Synonyma nicht \%usammenfinden ḳönnen, trotz der sorgfailtigsten Vergleichunir.

Auf Vollzähligkeit der Arten mache ich natïrlich keinen Anspruch; ieh besclureibe nur die ron mir selbst untersuchten. Ueber die Methode der Untersuchungen wüsste ich nichts Erlebliches beizubringen, als dass man sich mit Geduld wappnen muss, um vielleicht beim zwölften, zwan. 
zigsten Object etwas von feinerer Organisation zu sehen. Die Zeit der Beobachtungen genau anzugcben, ist bei ähnlichen Arbeiten, wie die meinige, nothwendig, weil man dadurch seinen Nachfolgern die Mühe erleiclitert und sich selbst ungerechten Widerspruch erspart.

Sämmtliche von mir beobachtete Species fanden sich in der Nähe des Dorfes Axien an der Elbe, zwischen Wittenberg und Torgau. Keine der neuen Arten ist mir anders wo vorgekommen, und es ist daher wünschenswerth, dass andere Fundorte mitgetheilt werden. Das Vorkommen so vieler Arten in so beschränkter Localitit, aus nur vier bis sechs kleinen Teichen und Tïmpeln, fordert ebenfalls zu weiteren Untersuchungen auf.

Dic Stelle und Geltung in zoologischen System, welche den $R$ habdocoelen in neueren Werken angewiesen wurde, ist sehr verschieden. Ehrenberg gründete zuerst in den Symbolis physicis die Klasse Turbellaria mit zwei Ordnungen, Deudrocoela und Rhabdocoela. Unsere Turbellaria rhabdocoela sind nur ein Theil der Ehrenberg'schen, nämlich diejenigen, welche Oersted als die dritte Familie seiner Pla nari e a beschreibt, wozu noch die Gattung Typhloplana von den Deudrocoelen gehört. Die ganze Abtheilung Plat $\mathrm{t}$ ï r m er zu nennen, hat nicht mehr Sinn als lucus a nou lucendo, denn die wenigsten dieser Thiere sind platt, viele ganz cylindrisch. v. Siebold in seiner vergleichenden Anatomic hat zwei Ordnungen der Strudelwürmer, die er als eigne Klasse aufstellt, Rhabdocoeli, in der Begrenzung wie die unsrigen, und $D$ eudrocoeli, die eigentlichen Planarien umfassend. Fs folgen dann bei r. Siebold die Rotatorien, 
und nun erst die Nemertinen als erste Unterordnung der Ringelwürmer, Ord. Apodes. In der Anatomie der wirbellosen Thiere von Frey und Leuckart (II. 'Theil der' Wagner'schen Zootomie) bilden wiederum die Nemertinen mit den Plattwürmern als Ordnungen die Unterklasse Strudelwürmer. Gleichbedeutend sind daher Plattwürmer Oersd. und Strudelwürmer Frey et Leuckart; ferner Planarien (Planariea) Oersd., Plattwïrmer (Planariae) Fr. et $L$. und Strudelwiirmer v. Siebld., wonach dann die Rhabdococlen bald als Familie, bald als Unterordnung oder als Ordnung figuriren. 


\section{I.}

Ueber die Organisation der Rhabdocoelen im Allgemeinen.

\section{Mautbedcckung. Nuskein。}

Die das äussere Flimmerepithelium der Strudelwürmer und insbesondere der Rhabdocoelen bildenden einzelnen Cilien sind von der äussersten Feinheit, mit Ausnahme nur weniger Species, z. B. Macrostomum hystrix. Auch kann man nie jene regelmässige, reihenweise Stellung der Flimmern wahrnehmen, die bei vielen Infusorien sich findet und auf besondere, die Cilienreihen in Bewegung setzende Muskelstreifen hindeutet. Unter dem Flimmerepithelium liegt eine farblose Zellenschicht, gewöhnlich von ansehnlicher Stärke.

Ein gesondertes Hautmuskelnetz, wie es sich bei den meisten Würmern findet, zeigen die Rhabdocoelen nicht. Auch die gewellten, zarten Fäden, die man leicht bei den durchsichtigen Mesostomeen bemerkt, haben nichts mit Muskelfasern gemein; bei allen Bewegungen des Körpers sind sie passiv. Ob nun durch das contractile Körperparenchym allein die 'Thiere oft so flink und leicht ihre Körperstellungen wechseln können, muss dahingestellt bleiben. Um der Ortsbewegung cine bestimmte Richtung auf ein 
pewisses Ziel zu geben, ist natülich nur, wie bei dem durch das Steue:ruder gerichteten Schiff, die entsprechende Stellung des Körpers nöthig, da die Fortbenegung selust durch das Flimmerepithelium geschieht. Aus einem dichten Muskelnetz ist der starke Mund fast aller der zu beschreibcuden Abtheilungen gebildet, auch werden andere gesonderte Muskeln, welche für die Bewegung eimzelner Organe bestimmt sind, an ihrem Orte beschrieben werden.

Die Bilung der sogrenannten stabfürmigen Körperchen gehört, in einigen Fällen wenigstens entschieden, nicht der Haut an. Bei vielen Mesostomeen kann man ihre Bildung in Zellen mitten in Körperparenchym leicht verfolgen. In birnformigen Zellen, die oft so zusammenhänggen, dass der verlängerte Stiel der einen his zur Kuppe der andern reicht, liegen sechs bis vierzehn der stabfö:migen Körperchen, die in dem spitzen Stielende der Zelle ihre gemeinschaftliche Basis zu haben scheinen, während sie sich nach oben, wo die Zelle erweitert ist, mehr aus einander falten. Die Entwickelung der stabförmigen Körperchen und das Emporsteigren der sie enthaltenden Zellen an die Oberhaut halten gleichen Schritt. Endlich wird die Zellenwand absorbit, und die Körperchen ragen einzeln aus der Ilaut hervor. So habe ich es am klarsten bei Mesositamum rostratum und tetragonum beobachtet. Es kommen jedoch auch mchrere Abweichungen vor. Die stabfömigen Körperchen finden sich auch schon bei den Fubryonen, doch habe ich hier ihre Entwickelung aus Zellen nicht gesehen. Bei Macrostomum hystrix sind diese Gebilde ron einer etwas anderen Form, indem sie (wie 
Oersted richtig abgebildet hat) zu drei, seltuer zu zwei keilförmig verbunden sind. Sie aber als ganz verschieden von denen der andern Rhabdocoelen anzusehen, erscheint nicht zulässig. Auch bei den Mesostomeen sind ja die Körperchen ursprünglich zu kleineren Gruppen vereinigt und bei Fortex iruncata treten sie gleichfalls zu zwei und drei verbunden in die Haut.

Um Wiederholungen zu vermeiden, sollen gleich hier alle Arten, bei denen die stabörmigen Körperchen von mir beobachtet sind, genannt werden. Fs sind: Vortex truncata, Vortex picta; Derostomum unipunctatum; Mesostomum lingua, rostralum, tetragonum, Eheubergii, personatum; Typhloplana viridata; Schizostomum; Microstomum leucops. Mögen Andere das nachzuholen versuchen, was mir nicht gelang, über die Function der Stähchen Aufschluss zu erhalten.

Ueber vereinzelte Hautgebilde, als die Borsten ron Macrostomum leystrix, die Angelorgane von Microstomum lineare, lese man bei diesen Arten nach.

\section{Rervensystenn. Sinnesogrante}

Ich bin nicht glücklicher gewesen als meine Vorgänger, indem ich durchaus nichts Sicheres über die Verbreitung von Nerven und Ganglien erkannt habe. Unten, bei der Beschreibung der Species, werden einige vereinzelte Beobachtungen mitgetheilt, die aber zu allgemeinen Schlüssen nicht berechtigen. Wir mïssen also glauben, es fehlen uns noch die Mittel, uns die Nerven der Rhabdocoelen deutlich zu machen. Unzweifelhaft ist es mir allerdings geworden, dass sehr oft die Pigmentflecke, welche man 
Augen nennt, in einer ganglienartigen Masse eingebettet liegen, welche eine Verdickung oder Ausbreitung eines Nerven zu sein scheint. Man erklärt also die im Vorderende vieler Arten bemerkbaren Pigmentanhäufungen für Augen, denen zwar lichtbrechende Medien fehlen, deren Nerven aber specifisch für Lichteindrücke empfänglich sind und darin ron dem Pigment unterstütat werden. Man hat bier um so mehr Grund dazu, als sich bei den Dendrococlen an der Stelle dieser Augenflecke ein wirklich lichtbrechender Apparat, Hornhaut, Glaskörper, Linse, findet. Auf eine eigenthümliche Structur in diesen Augenflecken dentet in einzelnen Wälen, z. B. bei einigen Derostomeen, die regelmässigge Gestalt, welche sie annehmen.

Gegen die rigmentilecke als Surrogat der bilderzeugenden Augen sind in neuerer Zeit vielfache $\mathbb{Z}$ weifel geltend gemacht, und ein vollständiger Beweis dafür wird auch nie gefülırt verden können. Ueber solche und älınliche Verhältuisse müssen daher die Ansichten inmer mehr oder weniger subjectiv bleiben, jenachdem man der Analogie eine grössere oder geringere Geltung zugesteht. Je behutsamer die Zoologen geworden sind, ähnliche Organe, rie die besprochenen, für Augen zu halten, desto freigebiger ist man mit Austheilung von Gehörorganen, wobei man aber, wenn man stricte Beweise fordert, nicht um ein llaar besser berathen ist, \%. B. bei den Rand-Körpern der Quallen. Bei der den Strudelwürmern verwandten Gruppe der Nemertinen sind die zu beiden Seiten des Kopfes befindlichen Spalten oder Grübchen mehrfach für Sinneso:gane erklärt worden, so ron $R$ athke (neuste Schriften der naturf. Gesellschaft in Danzig, 1842) für 
Gefühlsorgane, von Quatrefages (Amnales d. sc. $n$. 1846. Froriep's Not. April 1847) für Gehörorgane, den Gehörkapseln der Nollusken entsprechend. Bei den Mi. crostomeen finden sich ganz ähnliche Grïbchen, die mir aber nicht im Entferntesten Anlass geben, sie für Gehörorgane zu halten, vielmelir den Eindruck von Respirationsöffnungen machen.

Die ganze Körperoberfläche der Rhabdocoelen ist sehr empfindlich, da bei der geringsten Berührung die gereizte Stelle sich zusammenzicht. Besondere Tastwerkzeuge befinden sich ain Munde der Derostomeen.

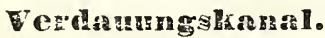

Nur in der Gruppe der Microstomeen ist der Verdauungskanal mit zwei Oeffnungen versehen, was ich gegen Oersted und andere Autoren behaupten muss, welche allen Planarien nur eine Mundöfnung zuschreiben. Die Microstomeen, langgestreckt und wurmförmig, sind schon durch die ihnen allein eigenthümliche Fortpflanzung durch Theilung auf die doppelte Oefinung des Darmkanals hingewiesen. Bei ihnen ist auch der Darmkanal in seiner ganzen Länge mit Flimmerepithelium ausgekleidet, dessen Vorhandensein bei den übrigen zweifelhaft ist. Im Allgemeinen ist der Mund der Rhabdocoelen sehr muskulös und wegen seiner mannigfaltigen Form und Lage geeignet, als wesentliches Merkmal fïr die Unterabtheilungen gebrauclit $z 0$ werden. Bci einigen findet sich ausser dem in den Magen fïhrenden Nund noch ein blinder Saugmund. Die Ansichten Oersı d's über die stufenweise Entwicke- 
lung des Mundes bei den Planarien äbertaupt und dann wiederholt in den einzelnen Abtheilungen können wir usicht theilen. Nachdem er gesagt: ,Von allen Organen sind die Zeugungsorgane diejenigen, die hier die löchste Entwickelung erlangt haben," behauptet er dasselbe zugleich von dem Darmkanal, indem es heisst: „In jeder natürlichen Gruppe findet sich ein Organ, auf welches die Natur gleichsam vorzugsweise ihre Aufmerksamkeit gelenkt zu baben scheint, da es auf Kosten der andern entwickelt zu sein scheint. Diese Gruppe ist denn der Ausdruck des Entwickelungscrelus dieses Organs, da es von seiner niedrigsten Stufe (thiesis) sich (durch die autithesis) zur Vollendung und zur Abschliessung (synthesis) hinautarbeitet. Bei den Planarien ist der Darmkanal, rorziglich aber der Mund dieses Organ." Die thesis soll nun in den Rhabdocoelen ihren Ausdruck finden. Also steht der Darmkanal den Rhabdocoelen, der dieselben histologischen und dynamischen Eigenschaften hat, wie der der Deudrocoelen, deswegen auf einer tieferen Stufe der Entwiclsclung, weil ihm die Blindsäcke fehlen? Auch ist es unmöglich, den Mund der IRhabdocoelen, im Gegensatz zu dens os distinclum der Dendrocoelen, indistinctum zu nennen. Man betrachte meine Abbildung Taf. II. Fig. $4^{b}$, und man whd davon abstehen. Erscheint ferner der Mund der Microsto. meen wirklich klein, so ist er doch keineswegs unvollk o m m ner als der der andern Gattmigen, da sich zahlreiche Muskeln an $\mathrm{ihm}$ finden, seine Leistungen dicselben sind, und die Microstomeen mit ihrem, einer grossen Erweiterung fähigen Munde eben so grosse Thiere geschickt benältigen, als die Uebrigen. Wir müssen 
es für ein undankbares Werk halten, in dieser Art logischen Schematismus der Natur aufzuzwingell.

\section{HBit - und Kespirations - System.}

Nachdem uns die vergleichende Anatomie eine Menge von Thatsachen an die Hand gegeben, aus denen hervorgeht, dass bei vielen Thieren ein Chylus und Blut führendes Gefässsystem, welches in capillaren Verzweigungen den Nahrungssaft den kleinsten Körpertheilen zuführt, nicht nothwendig ist, sondern dass theils die kapillaren Verbindungen und Uebergänge aus den Arterien in die Venen fehlen können, theils das Blut ganz ohne eigenthümliche Gefässe in der Leibeshöhle fluctuirt, kann es auch bei den Strudelwürmern nicht auffallen, wenn man ein gesondertes Blutgefässsystem nicht entdecken kann. Nun hat freilich die genauere Beobachtung gelehrt, dass oft da, wo ein der Respiration dienendes System von Luft-oder Wasser-Kanälen bekannt war, auch die wirklichen Blutgefässe, gewölnlich in unmittelbarer Verbindung mit den Respirationskanälen, nicht fehlen. Und so hat man denn Aufforderung genug, mit der grössten Vorsicht sein Urtheil über diese schwer zil erkennenden Verhältnisse abzugeben.

Indessen scheint wirklich den Rhabdocoeten (anders verbäit es sich wohl bei den Deudrocoelen) weder ein ganz noch ein theilweise geschlossenes Blutcirculationssystem zuzukommen, sondern das Blut frei an die Organe zu treten. So wenig es auch gelingt, wegen der Weichheit und Zartheit des Parenchyms, sich die Räumlichkeiten der Leibeshöhle klar zur Anschauung zu bringen, so deuten doch manche Umstïnde, z. B. die Leichtigkeit, mit der sich die 
Embryonen rom Kopfende bis zum Śchwanzende der Mutter bewegen, anf grosse, dem Blute offen stehende Lacunen hin. Man kann nun Chylus, arterielles und renöses Blut nicht mehr räumlich und also auch nicht nominell von einander scheiden, sondern nur im Allgemeinen von einer aus dem Magen durch Exosmose frei gewordenen ernährenden Flüssigkeit sprechen. Blut - und Chylus-Körperchen habe ich nicht gefunden.

Je weniger aber der Nahrungssaft Gelegenheit hat, als venös nach einem bestimmten Punkte hin geleitet zu werden, um dort die respiratorischen Umänderungen zu erleiden, desto mehr stellt sich das Bedürfniss heraus, dass über und durch den ganzen Körper für Respirationsorgane gesorgt ist, die es gar nicht zu einer Sonderung in taugliches und untaugliches Blut kommen lassen, sondern unausgesetzt an allen Orten ihren erneuenden, belebenden Einfiuss ausüben. Darf man nun sagen, dass jede lebensthätige Membran, jede Oberhaut, wo sie nicht in Hornbildung übergeht, respirirt, so ist doch insbesondere die Schleimhaut und dic Flimmerhaut der Respiration am günstigsten, und es wird daher mit vollem Rechte den Strudelwürmern eine Hautrespiration zugeschrieben.

Diese reicht aber, wie sich zeiggt, nicht aus, sondern es lässt sich ein eigenthümliches, sich im Innern des Körpers verbreitendes Wassergefüsssystem nachweisen. Was die früheren Beobachter abhielt, die hie und da von ihnen in den Rhabdocoelen bemerkten Gefässe für Wasserkanäle zu erklären, lag darin, dass ihnen die Oefinungen derselben nacl aussen unbekannt blieben. Nachdem ich diese gefunden, darf man ïber dic wahre Natur dieses 
Gefässsystems nicht in Zweifel sein. Wenn ich nicht irre, war es Burmeister, der solche Wassergef ässe mit den Tracheen verglieh, und in der 'That ist bei den Rhabdocoelen die Analogie ganz auffallend: symmetrisch zu beiden Seiten oder vereinigt in der Mittellinie des Körpers gelegene Oeffnungen, Stigmata, durch welehe das Wasser ein- und austreten kann; Hauptkanäle, in der Lünge des Thieres rechts und links verlaufend, und von diesen Stämmen ausgehende Verzweigungen, die ich zwar nicht überall bis in ihre feinsten Endungen habe verfolgen können, die aber auch nur, wegen ihrer Zartheit, unter besonders günstigen Bedingungen sichtbar werden und daher wohl der ganzen Gruppe zukommen. Oft ist durch die geringste Ortsreränderung des 'Thieres das noch eben klar' hervortretende Gefäss wie verschwunden, und dieser Fall tritt selbst bei den starken Seitenstämmen ein. Man könnte hierdurch zu der Annahme verleitet werden, als seien diese Kanäle nur Scheingefässe, denen eigene Wandungen fehl. ten. Diese sind aber vorhanden, wie ich mich durch einige vom Zufall herbeigeführte Isolirungen überzeugt habe, auch sprechen ohne diess die in den Kanälen schwingenden Flimnerlappen dafür. Das Vorkommen der Flimmerorgane scheint nicht an bestimmte Stcllen der Gefässe gebunden zu sein, sondern sie sind unregelmässig zerstreut. Ihr Zweck ist, wie wir wissen, die Flüssigkeit in den Gefässen in Bewegung zu setzen, doch würde wohl diese Vorrichtung allein nicht ausreichen, die Stagnation zu verhüten, und um das Wasser gänzlich zu erneuen, bedienen sich unsere Thiere desselben Manövers wie die Räderthiere u. a.; sie ziehen sich plötzlich zusammen und pressen 
so das Wasser aus den Gefässen hervor; bei der Ausdehnung wird dann frisches Wasser eingesogen. Auch ist ö ters an den Stigmen das äussere Flinmerepithelium besonders ausgebildet und thatig, so dass an diesen Mündungen die den ganzen Körper umspülende Wasserströmung verstärkt ist.

\section{Fort pflanzungssystem.}

Die von mir beobachteten Species, in denen ich Geschlechtswerkzeuge wahrnahm, sind Hermaphroditen mit gegenseitiger Befruchtung ${ }^{*}$ ). Sehr wahrscheinlich sind es auch die Nicrostomeen. Denn wenn anch Oersted's Mittheilungen ïber deren geschlechtliche Fortpflanzung sehr fragmentarisch sind, so lassen sie doch schliessen, dass bei ihnen die gewöhnliche Fortpflanzung durch Theilung periodisch pausirt, dann sich Geschlechtstheile entwickeln, und aus Eiern Junge gezogen werden. Ausser

*) Die ron Steenstrup gegen den Hermapliroditisnus erhobenen Zweifel haben zwar diese Lehre in ilıem Wesen nicht ersehültert, aber doch die heilsame Nachwirkung ansgeübt, dass sie zu genaueren Untersuchungen üher die Entwickelung des Samens Anlass gaben. Die von $\mathbf{S}$ tee $\mathbf{n}$ t $\mathbf{r}$ up beigebrachten philosophischen Gründe, dass die geschlechtliche Zengung auf dem Principe des Gegensatzes beruhe, dass die Gegensätze, in einem Indiviluum vereinigt, sich cinander aufheben müssten u. s. W., lassen sich sehr wohl hören, erweisen sich aber doch nicht als stichlaltig; und es ist Steenstrup, trots des Scharfsinnes, mit dem er seine Theorie der Hemmungsbildungen verficht, doch nicht gelungen, seiner Ausicht viele Freunde zu erwerben. Man würde zu den ahenteuerlichsten Annahmen genöthigt sein, wenn man den Heruaphroditismus der Strudelwümer lengnen wollte. 
bei den Microstomeen habe ich nie eine Spur von Quertheilung bemerkt.

$$
\text { S a m e n. }
$$

Die Hoden sind in der Regel grosse hufeisenförmige, birnförmige oder cylindrische Schläuche, die sich zwar isoliren lassen, jedoch schwerer als theile, weil sie fester mit dem zelligen Parenchym verwachsen sind. Der Samen wird in ihnen fertig bereitet und erreicht nicht erst, wie diess bei andern Würmern beobachtet, in dem weiblichen Geschlechtsapparate seine vollkommene Ausbildung. Im Hoden selbst kann man zwei Bestandtheile des Samens unterscheiden: Zellen, die sich niclat zu Zoospernien entwickein und bei der Befruchtung von sehr untergeordneter Bedeutung zu sein scheinen, da sie nie mit in die weiblichen Theile übergehen, und Zoospernien, gewöhnlich in verschiedenen Stufen der Entwickelung aus grösseren Zellen. Ob diese Zellen ursprünglich auch so auffallend in ihrer äusseren Erscheinung mit den Eikeimen übereinstimmen, wie man allgemein zu behaupten anfüngt und es noch neulich von Reichert (Müller's Archiv 47. Heft II) bei Strogylus auricularis und Ascaris acuminata bewiesen ist, habe ich nicht beobachten können. In dem frühsten Zustande, in dem sich mir das Zoospernion darstellte, war es ein langgezogenes, wasserhelles Bläschen ohne Inhalt, auf der einen Seite allmählig in einen kurzen Anltang übergehend. Das Bläschen wird kleiner und gerundeter und in eben dem Maasse streckt sich der Anhang. Die Verkleinerung und Abrundung des Bläschens geht jedoch nicht 


\section{6}

immer regelmässig vor sich, sondern es nimmt zuweilen eine unregelmässig eingeschnürte, lange Form an, deren vorderes Ende das Knöpfchen wird. Erst in den letzten Entwickelungsstadien wird das Zoospernion beweglich. Die allgemeinste Form ist die oben beschriebene, ein Knöpfchen mit fadenförmigem Anhange. Nur in einem einzigen Falle (bei Opistomum pallidum) tritt eine abweichende Form auf ("Taf. V. Fig. 14b). Oersted, der verschiedene Entwickelungsstufen bei rerschiedenen Species fand, liess sich dadurch verleiten, sie als Charaktere der Arten aufzustellen. Die Bewegung der Zoospernien ist am lebhaftesten, wenn sie aus dem Moden in die besonderen Blasen gelangt sind, von wo aus sie zur Befruchtung verwendet werden. Hier scheint oft ein gemeinsames Agens auf sie zu wirken, wenn plötzlich eine Wellenbewegung durch die ganze, nicht wirr durch einander liegende, sondern regelmässig geschichtete Masse geht.

$$
\text { D o t } t \text { er. }
$$

Die Dotterbereitung ist ganz unabhängig ron dem Keimstock und geht in gesonderten Organen vor sich. Die fertigen Dotterstöcke stellen sich entweder als grosse, mit Ausbuchtungen und Blindsäcken versehene Schläuche dar, mit ein em Ausführungsgange, oder es sind einzclne, von einer Membran umschlossene Zellenhaufen mit eben so vielen Ausführungsgängen. Auch die langgezogene Schlauchform scheint durch Resorption der Membranen der an einander stossenden grossen Zellen zu entstehen. Die Bildung des Dotters geschieht aus einer ganz durchsichtigen Flüssigkeit; es entstehen Brutzellen in grossen Mutterzellen. 
Aus der Flüssigkeit schlagen sich zuerst einzelne solide Körnchen nieder, die bald von vier bis sechs neuen Brutzellen, welche die Mutterzelle ausfüllen, unschlossen erscheinen. So geht die Zellenbildung weiter, während in der Folge die Wände der ersten und der in diesen entstandenen Brutzellen resorbirt werden, auch jene zuerst aus der Dotterflüssigkeit sich niederschlagenden Körnchen verschwinden. Als eigentlicher Dotter bleibt zuletzt eine homogene Masse durchsichtiger Zellen, die keinen Kern, oft aber noch kleinere Zellen enthalten. Die Membran der ursprünglichen Mutterzelle bleibt in vielen Fällen als Umhüllung der einzelnen Dotterhaufen.

Keime. Eibildung. Embryo.

Oft funfzig - bis sechzigmal kleiner als der Dotterstock ist der Keimstock, auch ein länglicher Schlauch, der eine nicht grosse Anzahl Keime enthält, zehn bis zwanzig, die gedrängt, gewöhnlich nur in einer Reilhe, neben einander liegen, so dass sie sich etwas eckig drücken. Den Hauptbestandtheil der Keime bilden Keimfleck und Keimbläschen, umgeben von einer Schicht fcinkörniger Masse, die auch sonst die von den Keimen gelassenen Zwischenräume im Keimstocke ausfüllt. Von hier gelangen die Keime einzeln in ein Organ, welches mit dem Dotterstock in Verbindung steht. Wohl in allen Fällen geschieht die Befruchtung während der Translokation des Keimes in diesen Sack, in welchem der Eidotter hinzutritt. Der zur Befruchtung dienende Same, bei vorangegangener Begattung aufgenommen, wird in selır allgemein verbreiteten Blasen aufbewahrt, die zum weiblichen 
Geschlechtsapparate gehören und den Samentaschen der Insectenweibchen 7,0 vergleichen sind. Der Dotter hat gewöhnlich bis zum Keine einen ziemlich weiten Weg zurïickzulegen durch den Bottergang, oft aber steht das Fi ausserdem durch einen langen durch den Dottergang sich erstreckenden hohlen Stiel mit dem Dottenstocke in Verbindung. Bei der Dotteranhäufung an den Keim rergrössert sich dieser, ist aber noch längere Zeit durch cine eigene Membran von der Dotterschicht getrennt. Wie lange diess dauert, labe ich wegen der zunehmenden Undurchsichtigkeit des Eies nicht beobachten können. Die Stelle des Keimbläschens wird aber in der Regrel bis zur beginnenden Biláung des Embryo durch einen hellen Fleck bezeichnet. Auch der Furchungsprocess hat an diesem Orte statt; ob aber daran der gesammte Eiinhalt Theil nimmt, also auch der sogenannte Nahrungrsdotter, und ob der ganze Vorgang hier noch zu Ende gefiihrt wird, ist mir ungewiss geblieben.

Nachdem das Ei genug Dotter an sich gezogen hat, bleibt entweder die äussere lederartige und durchsichtige Dotterhaut, indem sie nur eine schwach gelbliche Färbung annimmt, oder es bildet sich eine harte, undurchsichtige Schale, gelb oder rothbraun, ron beträchtlicher Stäke. Im letzteren Falle entstehen Eier, deren Embryonen sich nicht im Mutterleibe entwickeln, sondern welche langre Zeit eintrocknen oder einfrieren können, bis günstige Umstände, Feuchtigkeit und Wärme, ilıe Entwickelung begïnstigen. Diese Eier werden also nicht nur, wie man annahm, im Herbste gebildet, um zu überwintern, sondern man trifft sie zu jeder Jahreszeit. Viele Rhabdo- 
coelen finden sich in kleinen, durch Regen entstehenden Pfützen. Mit diesen trocknen die hartschaligen Eier ein und bewahren Wochen und Monate lang bei der grössten Hitze und Trockenheit ihre Lebensfähigkeit. Wie die Entomostraceen haben die Rhabdocoelen in Innern oft Oeltröpfchen, und diese findet man in den Sommer - und Wintereiern beider wieder, so dass dieses Oel wohl das Aufbewahrungsmittel für die Eier ist. Die Entwickelung des Embryo aus solchen Eiern muss sehr schnell vor sich gehen, indem ich oft bald nach einem Regen in kleinen Gewässern die Strudelwürmer zugleich mit den Entomostraceen zu Tausenden erstanden sab.

Die Entwickelung der im Mutterleibe auskriechenden Jungen ist kürzlich folgende: Das Ei streckt sich gewöhnlich zu einer elliptischen Form; dann wird in dem einen Ende der Dotter in eine ganz klare Flïssigkeit aufgelöst und die ersten wahrnehmbaren Theile des Embryo sind die Augenflecke. Es bildet sich von vorn nach hinten eine Haut, an der selar bald Wimpern und stabförmige Körperchen, erstere in voller Thätigkeit, sich unterscheiden lassen. Auch der Mund tritt nun hervor. Mit der Entfaltung dieser Organe verschwinden die von der Leibeshöhle des Embryo umschlossenen Dotterzellen mehr und mehr, sie sind jedoch selbst nach dem Auskriechen noch nicht ganz aufgezehrt. Ich bestätige hiermit die Vermuthung von Focke, dass das Junge sich noch eine Zeit lang von dem in sein Inneres aufgenommenen Dotter z.1 ernähren scheine. Die in sich gekrümmten Eubryonen bewegen sich im Fi sehr lebhaft. Nachden die Schale gep!atzt ist, bleiben sie noch einige Zeit frei im Mutterleibe, 
sind aber unempfindlich gegen eine künstliche Frühgeburt, indem sie dann ohne Schaden im Wasser fortleben und wachsen. Von Geschlechtstheilen ist in den Jungen kcine Spur zu bemerken, es findet sich aber doch in dieser Entwickelung nichts, was mit einer Metamorphose rerghidhen werden könnte. 


\section{着析。}

Specielle Beschreibung der beobachteten Arten.

Um das von den Autoren bisher mit Recht geltend gemachte Eintheilungsprincip, nach Stellung und Beschaffenheit des Mundes, beizubehalten, sind wir genöthigt, zu den von Oersted aufgestellten vier Abtheilungen ( $\mathbb{P r o}$ stomeae, Derositomeae, Mesostomeae, Microstomeae) noch zwei hinzuzufügen, die Opistomeae und Schizostomere. Wir nennen sie nicht Unterfamilien, sondern Familicn, da uns die ganze Gruppe hinlünglich den Rang einer Ordnung zu haben scheint.
Classis: Tubellaria.
Ordo: Thabdocoela.

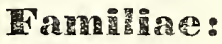

1. Prostomeae: Mund tonnenförmig, Oeffnung am Vorderende des Mundes und Körpers; Augen hinter dem Munde.

2. Derostomeae: Mund tonnenförmig, Oefinung etwas rom Vorderende des Körpers entfernt; Augen vor dem Munde.

3. Opistomeae: Mund tonnenförmig in Hintertheile des Körpers.

4. Me sost ome ae: Mund ring-oder kugelförmig, in der Mitte der Bauchfläche, vertical auf dem Darm. 
5. Schizostomeae: Nund cine Längsspilte, im Vordertheile des körpers.

6. Microstomeae: Mund im Vordertheile, mit kleiner, aber einer bedeutenden Erweiterung fähigen Oeffung. Körper nurnförmig. After vor handen. Fortpflanzung durch Quertheilung.

Dic Mesostomeen charakterisirt Oersted so: Aperlura oris infera. Os ammliforme verticale. Ocnli ori antepositi, proventriculus mullus. Dann sagt er: die Mundöflnung ist entweder auf der Mitte der Unterfläche oder sogar hinter derselben. Bei seinem Strongylostoma aber ist apertura oris ante medinm corpus. Auch scheint Strongylostoma (Plan. radiata Zool. Dan. Tab. 106. 1., nicht Tab. 406, wie bei $O$ ersted verdruckt ist) in der That so wenig vou den eigentlichen Mesostomeen abzuweichen, dass sie mit in diese Abtheilung gezählt werden kann. Ferner hat Oersted unter den Mesostomeen eine Typhloplana marina ,apertura oris infra mediun corpus." Diese ist nur in einem Exemplar gefundel, und von ihrer Organisation liess sich so gut wie nichts erkennen. Es muss daher einer späteren Untersuchung aufbehalten bleiben, ob diese Meerplanarie nicht vielleicht zu unsern Opistomeen gehört. Rechnet nun Oersted noch die Gattung Macrostoma "apertura oris infera, ab apice haud multum remota. Os ammliforme ovale, ex serie musculorum simplici constans ${ }^{6}$ zu den Mesostomeen, so wird dadurch jede Begränzung dieser Familie verwischt. Es schien mir daher unerlässlich, Macrostoma abzutrenuen, wobei ich freilich gestehen muss, dass der ganze äussere und innere Habitus auch nicht recht mit der Gattung, mit welcher ich es zusammenge- 
gestellt, in Einklang zu bringen ist. Ein verbessernder Tadel meiner Eintheilung ist mir sehr erwünscht.

Ob die Gattung Convoluta Oersted (Planaria convoluta Zool. Dan.) in die Familie der Microstomeen gehört, muss erst eine genauere Untersuchung, als wir sie jetzt haben, entscheiden. Mir ist es sehr unwahrscheinlich.

\section{Proslomeac.}

\section{Gatlung: Rrostomat.}

Die einzige Gattung wird durch die oben angegebenen Merkmale der Familie charakterisirt.

$$
\text { P. lineare Oersted. Waf. I. 1. 1a. 1b. }
$$

Gyrator hermaphroditus E $h b$ g. (Abh. d. Berl. Ac. 1835.)

Unsere Species ist am leichtesten zu erkennen an den zu beiden Seiten des Leibes sehr klar verlaufenden Gefässen und dem spitzen, in einer harten gestielten Scheide sich bewegenden Stachel am Hinterende.

Oersted setzte an die Stelle des von Ehrenberg dieser Species gegebenen Namens Gyrator hermaphledoditus den früher von $\mathrm{D}$ ujè $\mathrm{s}$ in weiterer Bedeutung gebrauchten Gattungsnamen Prostoma. Weder mit hermaphroditus noch mit lineare wird die Eigenthümlichlseit der Species bezeichnet. Aus Dujès' Abbildungen will ich nicht entscheiden, ob sein Derostoma notops unsere Species sei, wie Oersted annimmt. Ehrenberg ist unschlüssig, ob er jenes Derostoma mit einer Turbella oder Phaenocera identificiren soll.

Das Vorderende des muskulösen N'undes ist mit fein- 
nen Punkten dicht gezeichnet, die wahrscheinlich innere Papillen sind und vielleicht denen des bulbus oesophageus von Chaetogaster entsprechen. In den zwei hinteren Dritteln des Mundes bilden die Längs - und Quermuskeln ein dichtes in die Augen fallendes Netz. Der Mund verengert sich zu einem kurzen Schlunde, neben dem die ron einer deutlich wahrnehmbaren Nervenmasse umgebenen Augen liegen. Neben dem Schlunde verlaufen auch zwei von den musculi retractores des Mundes. Diese beiden Muskeln inseriren sich in dem Winkel, den die hintere Mundfliche mit dem Schlunde bildet, zwischen den Augen so, dass sie die Schlundröhre theilweise bedecken. Die beiden anderen Retractoren liegen mehr nach aussen und inseriren sich an der Seite des Mundes $(m . r)$. Die Magenlıöhle ist von sehr zarten und mit den übrigen Organen vielfach verwachsenen Wandungen umgeben. In der Mitte des Leibes, ganz an derselben Stelle, wo wir unten den Mund der Mesostomeen zu beschreiben haben, und mit diesem auch in seiner Structur übereinstimmend, befindet sich ein Saugnape. Dieser ist jedenfalls das in der Ehrenberg'schen Abbildung mit * bezeichnete unklare Organ, welches zur männlichen Samendrüse gehören sollte. Später scheint man nicht wieder darauf geachtet zu haben. Ist das Individuum, das man beobachtet, stark mit Speise gefïllt, so sieht man diesen Saugnapf nur sehr undeutlich und er tritt überhaupt selten in bestimmten Umrissen hervor; man muss ihn, um diese zu erlangen, durch Verschieben des Deckgläschens und dadurch hervorgebrachtes Umrollen des "Thieres, an die Seite zu bringen und dort hervorzupressen suchen. Das Thier bedient sich des Napfes, um sich an 
seine Beute anzusaugen, z. B. an ganz starke und ansehnliche Entomostraceen. Zur Ueberwälligung derselben dient ihm auch offenbar, wie ich direct bcobachtet, jenes zusammengesetzte Instrument, dessen Stachel aus dem Hintertheile herausgeschoben werden kann (Fig. 1. st). Ehrenberg nannte es das männliche Sexualorgan (spipula duplex), Oerst ed Zeugungsglied, ohne Gründe dafür anzugeben. Dass es ein zur Uebertragung des Samens dienendes Organ sei, davon kann, nach der folgenden Beschreibung, nicht die Rede sein. Zu einem Reizoder Kitzelorgan, etwa wie der Pfeil der Helix, möchte es, bei dem leicht verwundbaren Körper des Prostoma, auch etwas zu scharf sein, denn bei den heftigen Bewegungen, welche die Thiere mit dem Stachel ausführen, würden sie sich durch und durch stechen und anspiessen.

In Fig. $1^{a}$ ist das Organ in seiner natürliche Lage dargestellt, so wie es ganz in den Leib zurückgezogen ist. Die runde Scheide, nach dem Ende hin verengert, läuft in einen langen, sich oben verdickenden Stiel aus. An dieser Anschwellung setzen sich zwei Muskeln an ( $m$ ), welche das ganze Organ nach rechts und links ziehen und somit dem Stachel die Richtung geben. Der Stachel selbst, obgleich sehr spitz, scheint doch bis in die feine Spitze hohl zu sein, denn es befindet sich an seinem oberen Endo eine mit einer klaren Flüssigkeit erfüllte Blase (ves. v), die ich nicht anstehe für eine Giftblase zu erklären. Diẹ von dem Prostoma überfallenen Entomostraceen werden ähnlich matt, wie die von der Hydra umstrickten und be. täubten 'Thiere. In Fig. $1^{\mathrm{b}}$ ist der Stachel hervorgeschoben, wobei man den in der Verlängerung der Scheido 
liegenden und dieselbe gleichsam fortsetzenden Muskel bemerkt, durch dessen Verkürzung der Stich geschieht. Beim Einziehen des Stachels wirken noch ein oder zwei andere Muskeln, die sich am Ende des Scheiden-Muskels inseriren. Stachel, Scheide und Schaft sind nicht spröde, sondern lassen sich biegen. Durch Säure konnte ich sie nicht auflösen.

So augenfällig auch auf den ersten Blick die Wassergefässe $(v \cdot a)$ zu Tage liegen, so schwer ist es, sie genauer zu verfolgen. Sie verlaufen nicht so einfach, wie Ehrenberg es abgebildet hat, sondern anastomosiren unter einander und geben an verschiedenen Stellen, nitmentlich nach dem Intestinum, feine Verzweigungen ab. Besonders deutlich verfolgt man ihren geschlängelten Laul' im Hintertheile, und hier tritt nach einer Umbiegung jederseits das Hauptgefäss an die Oberfläche und mündet nach aussen, gewöhnlich in einer kugeligen Anschwellung. Auch weiter nach vorn scheinen sich eine oder zwei Mündungen zu finden. Wie sich die Gefässe in der Mundgegend rerhalten, weiss ich niclit.

In der Nähe des Keimstockes (ov) findet sich regelmässig die Zoospernien enthaltende weibliche Samentasche $(v$ z). Der Hoden $(t)$ ist ein länglicher Schlauch, zur Seite des Darmes. Die sparsam sich entwickelnden hartschaligen Eier sind von einer eigenthümlichen hellen Zone umgeben. Das Ei (beobachtet am 1. Mai) ist nicht ganz rund, sondern an dem einen Ende etwas in die Länge gezogen und mit einem kurzen Stiele rerschen, der in ein mit der hellen Zone zusammenhängendes Knöpfchen ausgeht. Die Zone ist wohl eine Flïssigkeit, in der das Ei 
schwimmt, es findet sich aber bei den übrigen Rhabdocoelen nichts dem Gleiches, und ich weiss eine genügende Deutung davon nicht zu geben. Der Eistiel kommt allerdings, wie sich aus den folgenden Beschreibungen ergiebt, ofter vor. Was das nie fehlende Organ $x$ sei, kann ich auch nicht erklären. Es ist eine Blase, Zoospernien enthaltend, die ziemlich constant in vier bis fünf rundlichen Ballen sich anhäufen. Einige Male glaubte ich eine Oeffnung der Blase nach aussen zu bemerken. Wahrscheinlich gehört sie zum männlichen Geschlechtsapparat, und die Samenballen sind einzelne Befruchtungs-Portionen. Der Dotterstock liegt in einzelnen Particen auf dem Magen. Man würde sich übrigens irren, wenn man glaubte, ich häite die Hoden mit dem Dotterstock verwechselt, wozu vielleicht die Abbildung, wo der Hoden mit seinem Inhalte aus Versehen des Steinzeichners fast so gezeichnet ist, als iı den folgenden Figuren der Dotterstock sich darstellt, Veranlassung geben könnte. Was Ehrenberg für die männliche Samendrüse ansah, war wahrscheinlich ein fast ausgebildetes, aber noch nicht mit harter Schale überzogenes Ei. Es stimmt fast mit dem von mir abgebildeten überein. Ovarium und weibliches Samenbehältniss sind bei Ehrenberg an ihrer Stelle, letzteres ohne genannt zu sein. Das Organ $x$ ist bei Ehrenberg als ein zweites Ovarium dargestellt, kann aber diese Function nicht haben, da sich nie Keime, sondern nur Zoospernien in ihm finden. 


\section{8 \\ 2. Perostomeae.}

Gattung: Eretex.

Munüöfnung am Ende des Mundes, der sich bisweilen vorn in eine kurze enge Röhre verlängert. Der Mund liegt mit dem Darm oder Magen in einer horizontalen Linie.

\section{V. truncata. Taf. I. 2.}

Plenaria truncata Zool. Dan.

Vortex truncata Ehrb. (Abh. d. Berl. Ac. 1835.)

Vorn fast rechtwinklich abgestutzt, nach hinten allmählig keilförmig zugespitzt. Die Farbe ist schwarzbraun, durch zwei verschiedene Pigmente, ein rein schwarzes und ein braunes, hervorgebracht. Eier elliptisch mit einem fadenförmigen Anhange. Körper abgeplattet.

In der Hautoberfiäche habe ich fast nie die stabförmigen Körperchen vermisst, nur verbergen sie sich leicht in der dunklern Farbe des 'Thieres, die Augen sind gewöhnlich wie ein Flalbmond gekrümmt. Es sind sehr dichte Pigmentflecke, die sich aber auch oft theilen, so dass vier Flecke, zwei auf jeder Seite, entstehen, von denen die vorderen etwas weiter nach innen gerückt sind. Nach Ehrenberg und Andern ist es abnorm, wenn die zwei Pigmentflecke jeder Seite in einander gezogen sind; mir ist das Verhältniss umgekehrt erschienen, jedenfalls darf man aber nicht viel darauf geben.

$\mathrm{Zu}$ beiden Seiten des kurzen Magens liegen die Dotterstöcke (vit). Die Anordnung der Geschlechtswerkzeuge stimmt im Wesentlichen mit denen von Hypostomum riride überein; so das Organ, welches von dem Hoden nach der gemeinschaftlichen Geschlechtsöffnung führt (d.e). Ich kann 
daher auf die ausführliche Beschreibung dieser Theile bei jener Art verweisen. Ich habe immer nur ein einziges hartschaliges Ei gefunden, zuerst am 3. Mai; es hat einen eigenthümlichen fadenförmigen Anhang (siehe d.Abb.), eine Fortsetzung der Schale. Vielleicht ist es ein Ueberbleibsel des Stieles, durch welchen das Ei, während der Dotter sich an den Keim legt, mit dem Dotterstocke zusammenhängt.

Was Ehrenberg für die männliche Samendrüse erkliirt hat (a. a. O. Taf. I. 3. $t$ ), ist mir nicht ganz klar geworden; ich vermuthe aus dem gewundenen Anhange des abgebildeten Organes, dass es ein noch mit ungefärbter Schale umgebenes Ei war. Die Dotterstöcke hielt Ehrenberg für Ovarien; Oersted nennt sie fadenförmige Körper und vermuthet, dass sie Samendrüsen sind.

In der Figur links ist das Thier ohne Pigment dargestellt, um die Lage der Eingeweide deutlich zu machen. Das selur feinkörnige Pigment liegt nicht in der Haut, sondern in dem tieferen Parenchym.

$$
\text { I. pict a Nobis. Taf. I. } 3 .
$$

Vorn abgerundet. Körper cylindrisch. Das Mundende kann in eine kurze enge Röhre verlängert werden. Eier elliptisch, ohne Anhang. Die Färbung ist sehr variirend, bunt.

Diese Art ist von der vorigen leicht durch ihre Färbung zu unterscheiden. Während die Dotterstöcke bläılich, der Magen grün oder braun dürchscheint, hat der übrige durchscheinende Körper einen rosenrothen oder gelblichen Anflug. Es ist mir nicht geviss geworden, ob 
der Hoden doppelt vorhanden ist; er zieht sich unter dem Dotterstock hin, bis in die Nähe des sehr grossen Mundes. Ich fand in ihm am 3. Nai ausgebildete und noch unentwickelte Zoospernien, zugleich im Hinterende unterhalb des verhältnissmässig grossen Keimsackes ein fertiges, hartschaliges Ei. Auch bei dieser Species ist die Eibildung sparsam, wenngleich der Keimsack viele Keine enthält, deren ich gegen dreissig gezählt habe.

Das Thier wurde in grosser Nenge im Mai gefunden, in kleinen von Viehheerden besuchten Teichen. Es ist oft kleiner als Hydatina senta und sehr munter.

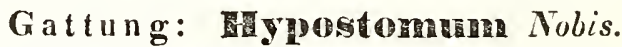

Der Mund, mit weiter an der Bauchseite gelegener Oeffnung, geht von hier schräg nach oben und bildet mit dem fast kugelrunden Magen einen Winkel.

\section{II. viride Nobis. Taf. I. 4. $4^{\text {a }}$. Taf. II. $4^{\text {bo. }}$}

Der Körper ist cylindrisch, nur zwei- bis dreimal so lang als breit. Hinten verschmäclitigt er sich schnell von der Rïckenseite in einen spitz auslaufenden Schwanz. Die Farbe ist ein schönes Blattgrün, was aber nicht, wie sonst von einem fein zertheilten Pigmente, sondern von grösseren grünen Kügelchen herrührt, welche in grosser Menge zwischen dem wasserklaren Parenchym eingestreut sind und durchaus jener körnigen Masse gleichen, welche man in Innern vieler Infusorien findet.

Die Augen, wie bei der rorhergehenden Gattung, halbmondförmig gekrümmt, sind mit der concaven Seite nach unten gewendet. In ihrer Näle habe ich einige Male 
ganglienartige Körperchen bemerkt, von denen sich Nervenfäden fortzusetzen schienen.

Der Verdauungskanal ist leicht zu isoliren (Fig. $4^{b}$ ). Die Mundöffnung ist mit sehr feinen Tastorganen umkränzt, papillenartigen Zellen, auf deren jeder ein stärker hervorragender Fühlfaden und um diesen herum ein Büschel äusserst zarter Härchen eingepflanzt ist $(p)$. Die Papillen mit den Fühlfäden sind für gewöhnlich in die Mundhöhle zurückgezogen und werden nur entfaltet, wenn das Thier sich zum Fressen anschickt. Aehnliche Organe sind von $\mathrm{Oersted}$ von Vortex littoralis beschrieben. $\mathrm{Er}$ meint, dass sie die Zühne ersetzen, was bei Hyp. viride sicher nicht der Fall ist.

Am Munde bemerkt man sehr leicht die doppelte Muskelschicht, Ringfasern und Längsfasern, die ein dichtes, starkes Gewebe bilden. Mit dem Munde reisst man gewöhnlich mehrere Muskeln los, die jenen in seiner Lage erhalten, an die äussere Körperwandung befestigen und als Retractoren wirken. Herrorgezogen wird er durch Muskeln, welche von der Oefinung uninittelbar in die Haut umbiegen. Zwischen Mund und Magen ist eine schmale Verengerung $(c)$, aus eigenthümlichen flockigen Zellen gebildet, die den Eindruck einer drüsigen Masse machen und also vielleicht einen Speichel absondern. Der fast eben so breite als lange kugelige Magen ist vorzugsweise aus einer dicken Schicht Pflasterzellen gebildet, die einen unregelmässigen Kern zeigen. Dass die innere Wandung mit einem Flimmerepithelium überzogen ist, ist mir sehr unwahrscheinlich. Es wird aber sehr viel Schleim nach innen abgesondert, der die eingenommene Nahrung umhüllt und 
sich mit ihnen zu einzelnen schwer zu trennenden Ballen verbindet.

Gefässe mit Flimmerläppchen habe ich oft gesehen, sie liessen sich sogar isoliren, ohne dass die Thätigkeit der Flimmern gehemmt wurde; dagegen liess sich die Anordnung des Gefässsystems nicht verfolgren.

Ueber die Geschlechtswerkzeuge glaube ich nach vieler Mühe mit ziemlicher Sicherheit Auskunft geben zu können. Um mir das Präparat für das Mikroskop zu verschafien, zerdrückte ich theils die Thiere behutsam mit dem Deckgläschen, theils zerlegte ich sie mit Nadeln. Schon mit unbewafnetem Auge sieht man am Rücken den geweilförmigen, gelblichen oder weisslichen Dotterstock durchschimmern (4a vit). Es ist ein zusammenhängender Schlauch mit vielen unregelmässigen Ausbuchtungen und Blindsäcken, die jedoch oft nicht ganz mit Dotterkügelchen ausgefüllt sind und dann eine klare Bildungsflüssigkeit enthalten. Die beiden seitlichen Aeste vereinigen sich linten, und hier setzt sich ein sehr leicht zu zerreissender Kanal an $(d . v)$, den man nur selten, indem man ihn sehr vorsichtig mit Hülfe feiner Nadeln bloszulegen sucht, sich zur Anschauung bringt. In diesen Kanal mündet zunächst, vom Dotterstock an gerechnet, und diess ist auffallend, die weibliche Samentasche (ves. $z$ ), cine kuglige Blase, fast immer voll Zoospernien. Sie löst sich leicht ab. Unmittelbar unter ihr ist der Keimsack $(o v)$. Beim Austritt des Kreines in den Kanal $d . v$ entleert wahrscheinlich auch die Blase ves. $z$ einen Theil ihres bei der Copula von einem andern Individum aufgenommenen Inkaltes zur Befruchtungr. Der Kein gleitet nun den Kanal hinab und gelangt 
in den Sack $s$. In diesen steigt auch der Dotter herab, der sich zur Bildung des vollkommenen Eies um die Keime legen soll. Während dieses Vorganges reicht ein Stiel vom Ei bis hoch in den Kanal, wahrscheinlich bis zum Dotterstocke hinauf und ich vermuthe, wie ich schon oben erwähnte, dass der fadenförmige Anhang der Eier von Vortex truncata ursprünglich ein solcher der Leitung des Dotters dienender hohler Stiel ist. In $s$ bildet sich auch die harte Eischale. Wie nun das Ei ron hier in die Bauchhöhle gelangt, habe ich nicht beobachten können, da mir der Behälter $s$ keine Oeffnung dahin zu haben schien; entschieden ist aber eine Oeffnung nach aussen vorhanden durch $c l$. In diesem kurzen Rohre $c l$ ist auch die Mündung des männlichen Geschlechtsapparates. Der Hode $(t)$ ist birnförmig. Es hat mir mitunter scheinen wollen, als ob er doppeit vorhanden sei, indess bin ich darüber nicht zur Gewissheit gekommen. Wenn man ihn bloslegt, reisst man gewöhnlich aus dem Parenchym Zellen los, die durch feine Fäden mit dem Hoden in Verbindung stehen und ihm wahrscheinlich Sifte zufihtren.

Je näher dem vas deferens $(v, d)$, desto seltener werden die Körnchen und Zellen im Samen, bis man in v. $d$ nur Zoospernien bernerkt. Zwischen dem Hoden mit seinem vas deferens und der Geschlechtsöffnung liegt nun ein höchst eigenthümliches Organ, welches zwar auch die Gattung Vortex hat, das wir aber erst hier näher ins Auge fassen wollen, weil sich unsere Art noch am Besten zur Untersuchung eignet. Es ist eine langgezogene, an der Einmündungsstelle des vas deforens abgerundete Blase, welche weiter unten in zwei harte elastische Schienen 
ibbergeht. Von der Steile an, wo die Selienen durch cinen Querbalken verbunden sind, sind sie nach aussen geboren, um bald wieder, wo das ganze Organ in $c l$ ausgreht, sich einander zu mähern. Tom Querbalken aus und von den gebogenen Schenkeln erstrecken sich je zwölf bis achtzehn Lamellen nach der Mittellinie zu, die fächerartig zusammengefaltet sind und nur unter starkem Drucke sich aus einander legen. Durch diese Lamellen wird eine Art von Mulde gebildet. Im oberen Ende der Blase ist eine zweite längrliche Blase cingeschachtelt (ves. s), die wohl die eigentliche Samenblase ist, aus der sich bei der Begattung der Samen entleert. Sie enthält immer einen Knäuel Zoospernien, und von ihr fïhrt ein Gang ( $d . e)$ abwärts zwischen jenen Lamellen hindurch zur Geschlechtsöfnung. Das Organ scheint bei der Begattung ansehnlich weit aus der Geschlechtsöfnung herausgeschoben werden zu können, welche sich an Rücken, unweit des Schwanzendes befindet.

Hält man die Thiere in einem kleinen Glase, so kann man die Begatung oft beobachten. Als Vorbereitung dazu verfolgen sie sich gegenseitig, schwimmen um einander herum und spielen, dann legen sie sich mit der Bauchseite gegen einander, aber nicht Kopf gegen $\mathbf{K} o p f$. Sich krümmend bilden sie fast eine Kugel und so drehen sie sich eine Weile im Wasser schwebend herum, bis sich die Schwanzenden mehr und melr nähern, und die Berührung der pori genitales erfolgt. Diess ist nur dadurch möglich, dass die betreffenden Stellen weit hervorgepresst werden, wie man mit blossen Augen sehen kann. Immer 


\section{5}

trugen beide sich begattende Indiviuen sehr völlig ausgebildete Eier.

Ich fand Hypostomum viride zuerst am 31. März in einem kleinen, von einer Elbüberschwemmung gefüllten Teiche, dessen Grund mit Schilf und Gräsern bewachsen war. An diesem und den folgenden Tagen war von Eiern noch nichts zu sehen. Am 10. April hatten 5 Individuen von 25 ein $\mathrm{Ei}$. Am 15. April hatten die meisten ein oder zwei Eier, einzelne vier und fünf. Am 22. April waren unter 28 Thieren die Eier so vertheilt:

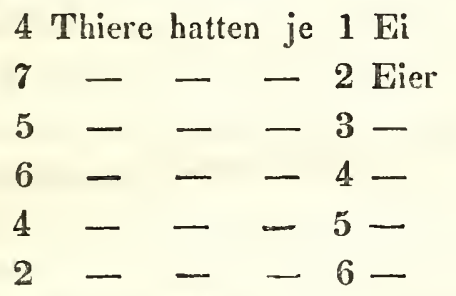

Am 23. hatte ein Thier 7 Eier, am 29. 8, am 1. Mai 9. Sieben bis zehn Eier waren dann die gewöhnliche Anzahl. Diess giebt eine ungefähre Vorstellung von der zur Eibildung nöthigen Zeit. Je mehr Eier entstehen, desto mehr drängen sie sich in der Leibeshöhle nach vorn bis ganz in die Nähe des Mundes. In meinen Beobachtungen wurde ich dureh einen abermaligen Austritt der Elbe unterbrochen. Lebendiggebären und Entwicklung des Embryo zeigte sich mir nicht.

\section{G a t ung: Herostomenne, O ersd.}

Der von $D$ ujès eingeführte Gattungsname Derostoma umfasst mehrere verschiedene Gattungen. Wir beschränken mit Oersted die Gattung auf die Species mit ton- 
nenförmigem Munde, dessen Oeflinng eine Längsspalte an der Interseite ist.

D. unipunctatum Oersd. Taf. II. 5. 5a. 5i.

Vorausgesetzt, dass wir die ron Oersted nur mit wenigen Worten beschriebene Art ror uns haben, müssen wir bemerken, dass der Specialname nicht passend einem ganz unwesentlichen Charakter, einem zufälig beobachteten Eie entlehnt ist. Ich behaite ihn bei aus Scheu ror neven Synonymen.

Dei rorn abgerundete, nach hinten breiter werdende und dann in eine stumpfe Spitze auslaufende Körper variirt sehr in der Färbung, wenigstens glaube ich die Varietäten, die ich fand, zu einer Species rechnen zu müssen. Am 21. April war das Thier nur einzeln zu haben, und da sah es weisslich und hiassgrün aus. Später war die Farbe ein schmutziges Gelbbraun. Der Mund ist sehr durchscheinend und distinct, der Magen aber nur in unbestimmten Umrissen zu erkennen, so nit dem Körperparenchym verwachsen, dass man ihn nie, wie bei Hypostomum, trennen kann. Gleich hinter dem Munde liegen die Geschlechtsrerkzeuge (5. gen. und $5^{b}$.), die sich recht. wohl auf die der vorigen Gattungen zurückführen lassen, obgleich ich den Ausführungsgang des Dotterstockes und den Zusammenhang des nach hinten sich verbreitenden Hoden mit dem bei der Begattung den Samen ausfuhrenden Organe nicht erkannt habe. Dieses letztere ist in Fig. 5 b die mittlere, zwischen dem Keimstocke $(o r)$ und der weiblichen Samentasche $(v, z)$ befindliche birnförmige Blase. Sie entbält die kleinere Blase $(r, s)$. der res. $s$ Fig. 4 ent- 
sprechend, und einen stempel $d$. e., Jer wohl ein Begattungsglied ist mit dem eigentlichen ductus eiaculatorius. In die nach aussen fülurende Mündung ct geht auch rom Keimstock ein längerer Kanal. Die Keime gehen aber in den Sack $s$, wo sie sich mit dem Dotter und der Schalc auskleiden. Obgleich etwas Unwahrscheinliches in dieser Anordnung liegt, so habe ich doch zu viele Individuen untersucht, als dass ich an eine wesentliche Täuschung glauben könnte.

Der völlig ausgebildete Dotterstock hat grosse Blindsäcke, wie sie sonst nicht vorkommen. Ehe die Eischalus erhärtet, sieht sie oft grü̈n aus.

Unter günstigen Unständen (dahin gehört geringe Ausdelınung des Dotterstockes und der stabförmigen $\mathrm{Käs}$ perchen, blasse Körperfarbe, Leerheit des Magrens) kann man die Verästelungen der Wassergefiisse sehr weit verfolgen. Es sind hier zwei getrennte seilliche Partieen, deren Mündungen sich nicht, wie bei den Mesostomeen, in unmittelbarer Nähe des Mundes befindell, sondern ziemlich weit nach hinten gerückt sind. In der Wund - und Augrengcogend nahm ich. an den starken geschlänggelten Gefässen wenige oder keine Àbzweigungen wahr, aber in der zweiten Körperhälfte sind sie vielfach verästelt, bis die Kanäle zum Verschwinden düun werden, ohne sich mit einander za verbinden. Symmetrisch regelmiissigy sind seibst die gröbereis Verästelungen nicht, auch finden sich mannichlache individuelle $\Lambda$ bweichungen. Die Mündungen sind constant. Wer wollte hier dic Analogie mit den Tracheen rerkennen!

Diese Art schwinmt weniger getn frei in Llarem Wasser unher, sondern liebt den Schlamm, unter welchem ich 
sie umherkriechend und wühlend zu Ende Juni in grosser Anzahl fand, in Gesellschaft einer gleichfalls schlammliebenden neuen Naide ${ }^{*}$ ).

\section{Opistomeac.}

Gattung: pistomener $N$.

Die Gattung ist in der Familie characterisirt.

O. pallidum Nobis. Taf. V. 14. 14a. 14b.

Körper zungenförmig, weisslich, durchscheinend, augenlos. Der Mund gleicht an Form und Structur ganz dem der Derostomeen; seine an der Bauchseite gelegene Oeffnung ist dem Vorderende des Körpers zugewendet, und mit dem sich bis vor die Dotterstöcke erstreckenden Magen bildet er einen spitzen Winkel. Man nimmt an ihm leicht die schon beschriebenen Muskelschichten wahr. Die Wandungen des Magens gehen unmerklich in das Körperparenchym über und bieten keine aufiallenden Erscheinungen dar.

Desto complicirter sind die Geschlechtsorgane. Der einfache Hoden $(t)$ hat die gewöhnliche längliche Gestalt. Ich fand die ausgebildeten $\mathbb{Z}$ oospernien besonders am Rande angehäuft, während die noch unentwickelten und das körnige Element des Samens die Mitte einnehmen. Dieser Strudelwurm ist der einzige, dessen Zoospernien die abweichende Form Fig. 14b zeigen. In einer Ausbuchtung des Hoden zu einer grestielten Blase $\left(t^{\prime}\right)$ findet rorzugs-

") Vergl. meine Mitheilungen daruber in Froriep's Notizen N. 65. August 1847. 
weise eine Ansammlung von Zoospernien statt, die sich hier zu einem kugeligen Bündel schichten Der Ausführungsgang des Hoden scheint sich indessen an dem hintern Ende zu finden, und ich vermuthe, dass der mit $v . d$. bezeichnete Kanal das vas deferens ist, obschon ich seinen Zusammenhang mit dem Floden nicht direct beobachtet habe; er war immer, wenn ich das Object unter dem Mikroskop etwas zusammendrückte, abgerissen. Der Kanal führt in ein sonderbares Organ, ähnlich einer dickbäuchigen Flasche $(h)$. Von dem Halse aus erstreckt sich in die Flasche hinein eir anderer sehr feiner Kanal, die Fortsetzung des vas deferens. Er verschmächtigt sich allmählig und ist auf der Aussenseite dicht mit festen, rückwärts gerichteten Stacheln und Widerhaken besetzt (14 a). Neben dem starken Ende liegen zwei grössere isolirte Stacheln, welche durchaus einem Pflugschar gleichen. Das dünnere Ende des Kanals führt zu einer Blase $(n)$, dicht gefüllt mit Zoospernien. Aus dem flaschenförmigen Organ geht wiederum ein Gang in eine Blase $(s)$, worin wahrscheinlich die Bef:uchtung des Eies und die Anhäufung des Dotters um den Keim stattindet. Gang und Blase wimmelten von Zoospernien, die sich namentlich dicht um das Ei gelegt hatten. In der Nähe befindet sich auch die schon öfter besprochene weibliche Samentasche $(v . z)$, deren Zusammenhang mit den übrigen Organen ich aber nicht ermittelt habe. Der Dotterstock besteht aus zwei parallelen Schläuchen ohne Ausbuchtungen, die sich zu einem gemeinschaftlichen Ausführungsgange vereinigen.

So wenig befriedigend diese lückenhafte Darstellung der Geschlechtsverhältnisse rom Opistomum sein mag, so 
interessant wird es für spätere Untersucher sein, die Analogieen mit den Fortpflanzungsorganen der Derostomeen zu verfolgen. Ich habe leider nur wenige Exemplare in den erstell 'Tagen des April beobachten können, geschöpft aus demselben 'Teiche, in welchem sich Hypost. vir. in grosser Menge aufhielt.

\section{Resosiomear.}

\section{Gattung: Mesostomum.}

Der Mund in der Mitte oder etwas vor der Mitte der Bauchseite. Zwei Augen.

M. Lingu a Nobis. Taf. II. Fig. 6-6c. Planaria Lingua Zool. Dan.?

Die Beschreibung, welche in der Zoologia Danica ron der Plan. Lingua gegeben wird, passt so ziemlich auf die vorliegende Art. Sie Jautet: "Planaria oculis binis, pellucida, fusco-cinerea, utraque extremitate obtutissina antica tamen paulo magis producta."

Der Körper ist weder vorn noch hinten zugespitzt, wie bei der folgenden Species, das Vorderende jedoch etwas mehr in die Länge gezogen. Die nahe bei einander liegenden Augen sind fast dreikantig; die Farbe ist ein schmutziges Gelb oder Braungelb.

In unmittelbarer Nähe des Mundes ist die Oeffnung der Wassergefässe (e). In Fig. 6 b sind die Hauptstämme des Wassergefässsystems dargestellt. Nachdem sie von der Oeflnnng und der Mittellinie des Körpers nach der Seite getreten sind, biegen sie fast nnter einem rechten Winkel 
nach hinten, wo sie sich mannichfach zu verästeln scheinen. Jedoch geht ein starker Stamm von hier aus wieder nach vorn bis in die Nähe der Augen. Hier habe ich in mehreren Fällen die blinde Endigung, wie die Abbildung sie zeigt, beobachtet; mitunter vereinigen sich aber die Kanäle, indem sie eine Schlinge bilden. Gleichfalls in der Nähe des Mundes liegen die Geschlechtswerkzeuge und die Geschlechtsöfinung. Die Anordnung ist im Ganzen dieselbe, wie sie F ocke bei Mesostomum Elrenbergii beschrieben hat. In der Deutung aber zwingen mich meine Beobachtungen, zum Theil wesentlich ron diesem und andern ihm folgenden Untersuchern abzuweichen. Nach Focke ist das cylindrische Organ 6 a $o v$ mit der Blase $v$. $z^{\prime}$ Penis; es kann aber, wie ich zeigen werde, weder ein zur Ausführung des Samens dienendes Glied, noch ein blosses Reizorgan sein. Es liegt immer seitlich hinter dem Munde, keiner der Beobacliter spricht von einer Oeflnung an seinem Ende, und, was das Wichtigste ist, die einzig wahrnehmbare Geschlechtsöfinung $(p . g)$ ist so gelegen, dass unmöglich der vermeintliche Penis aus ihr hervortreten kann. Eine andere eigene Oeffnung dafür ist, wie gesagt, nicht zu finden; es ist auch nicht wahrscheinlich, dass sie übersehen ist, da die Lage des Organs constant ist, also die Richtung, in der man zu suchen hat, angegeben. - Mir ist es nun unzweifellaft geworden, dass der hintere Theil des Cylinders ( $o v)$ der Keimsack ist, dessen Grösse auch in der Familie der Mesostomeen gegen die oft sehr ausgedehnten Dotterstöcke ganz zurücktritt. Es ist der Keimstock, den wir bei allen vorhergehenden Gattungen haben kennen lernen, und den man darum an dieser Stelle gar 
nicht vermuthen konnte, weil man überhaupt die Trenning der Dotterstöcke von den Keimstöcken bisher nicht kannte. Oersted (in seinem Buche über die Plattwürmer Taf. III. 52) hat sogar unbewusst die Kreime mit abgebildet. In einigen Fällen gelango es mir vollkommen, die in einer körnigen Flüssigkeit eingebetteten KKe eime herauszudrücken und einzeln zu messen. Sie gleichen durchaus den früher beschriebenen.

Riun aber gelangen wir zu noch ungelösten Räthseln. Auf den fein geringelten Theil des Cylinders folght eine Blase $\left(v z^{\prime}\right)$, welche ich immer mit einem dichten Gewirre von $\mathbb{Z}_{0}$ ospernien erfülit fand. Müssen die Keime durch diese Blase wandern? Fast scheint es so; denn der Ausführungsgang der Blase ist ein enger Kanal $(t)$, in welchen wiederum dic Ausführungrsgånge der einzelnen Portionen der Dotterstöcke einmünden $(d \cdot v)$. Der Kanal $t$ endet in einer zweiten Biase ( $s$ ), deren kurzer Hals zu dem porus genitalis führt; noch eine gestielte Blase $\left(v z^{\prime \prime}\right)$, Zoospernien enthaltend, mündet in $s$. Der Fioden ist (doppeit?) ein langer Schlauch, zur Seite des Darmes, zum Theil auf diesem liegend (Fig. 6. $t$ ); in ihrr traf ich oft die Zoospernien in den verschiedenen Entwickelungsstufen Fig. $6 \mathrm{c}$ an.

Am 25. April, wo ich Hes. Lingua in einem kleinen Exemplare zuerst beobachtete, waren die Generationsorgane noch nicht vollständig entwickelt; am deutlichsten trat der Hoden herror. Das abgelildete Exemplar mit den Jungen im Leibe ist rom 13. Juni. Dabei war der Hoden strotzend mit Zoospernien erfüllt, ebenso waren die Dotterstöcke voll. Durch die durchsichtige Eischale liessen sich 
leicht die stabförmigen Körperchen des Embryo bemerken. Neben den ausgekrochenen Embryonen lagen die verlassenen Eischalen. Die Jungen haben noch nicht die etwas plumpe Gestalt der Mutter, sondern sind schlanker. Die fertigen Wintereier sind rothbraun; mitunter trifit man noch nicht ganz erhärtete Schalen von grasgrïner Farbe an. Der Durchmesser eines aus dem Keimstock genommenen Keims verhält sich zu dem eines hartschaligen Eies wie 0,001 P. Z. zu 0,012 P. Z., der Inhalt aber nicht wie 1: $12^{3}$, da die Wintereier abgeplattet sind ${ }^{*}$ ). Auch kommt ein gut Theil auf die dicke Schale. Immer aber ist der Unterschied ein sehr erheblicher.

\section{MI. rostraium Dujès. Taf. III. 7. 7a.}

Planaria rostrata Zool. Dan.

Der sehr zarte, durchsichtige Körper ist an beiden Euden verschmälert, vorn rüsselartig ausgezogen. Die Farbe ist ein in der Mitte intensiveres, nach den Rü̈ndern zu verschwimmendes Rosenroth. Die Augen der mir zu Gesicht gekommenen Exemplare waren schwarz, nicht, wie andere Schriftsteller angeben, roth. Die geschlängelten Fäden, namentlich im Vordertheile wahrzuehmen $(y)$, kann ich eben so wenig, wie unten bei Mesostomum Ehrenbergii, für Muskeln halten. Auch hier liegen die Zeugungsorgane gleich hinter dem Nunde. Die Dotterstöcke sind einzelne Zellenhaufen. Nur ein einziges Mal schien es mir, als ob die hartschaligen Eier von einem gemeinsamen Behälter unschlossen wären. Ueber die strahligen Anhänge des

•) Vergl. Mcsostomun tetrağonum. 
Mundes vergleiche man die folgende Art. Sehr klar lässt sich an $\boldsymbol{M}$. rostr. die Entwicklung der stabförnigen Körperchen in tief im Parenchym gelegenen Zellen verfolgen. Völlig entwickelt und an die Oberfläche getreten sind die Stäbchen besonders von den Augen bis zum Vorderende, gewöhnlich in zwei Reihen, angehäuft. Da nun das Thier namentlich mit diesem Rüssel zu tasten scheint, ihn beim Schwimmen, gleichsam um den ersten Anstoss daran zu vermeiden, etwas in die Höhe gebogen trägt und überhaupt hier die grösste Empfindlichkeit zeigt, so liegt die Vermuthung nahe, dass die stabförmigen Körperchen ein Sitz feineren Gefühlsvermögens seien. Oersted spricht von eigenthüılichen Muskelbunden, jedes umgeben von einer durchsichtigen Scheide, die in regelmässigen Entfernungen mit Einsclnürungen versehen sei. Dass dies offenbar die stabförmigen Körperchen und ihre sie anfïllenden Zellen sind, hat schon v. Siebold in seiner vergleichenden Anatomie bemerkt.

\section{N. tetragonum. Taf. III. Fig. 8-8c. \\ Planaria tetragona Zool. Dan.}

Die Kanten des fast vierseitigen Körpers breiten sich in vier dünne Lamellen aus. Die Farbe ist ein ins Röthliche und Gelbliche stechendes Braun.

Die späteren Untersucher haben diese von $M \ddot{i} l l e r$ vortrefflich charakterisirte und ganz leidlich abgebildete Art fallen lassen und sie mit M. Ehrenbergii vereinigt. Wir mïssen sie aber wieder in ihre Rechte einsetzen. In der Zool. Dan. wird sie so beschrieben: Corpus tetragonum, lamellis quatuor pellucide luteis longitudinalibus axi cor- 
poris aduatis, versus extremitates sensim latitudine decrescentibus. Utraque extremitas acuta, antica magis attemuata. In angulis inter lamellas ovula fusca plurima transparent. Oculi duo puncta nigra, versus apicem anteriorem quoris latere transparentia. Dum animal libere natat, lamellae ad angulum rectum aequaliter inter se distant (wie im Querdurchschnitt Fig. 8a zu sehen), si vero supra solidum corpus incedit, lamellae binae inferiores extenduntur in planum, superioribus erectis. - Habitat in stagnorum et fovearum aqua puriori haud vulgaris.

Hat man das Thier auf einem Glasplättchen ausserhalb des Wassers, so legen sich die Lamellen der beiden Seiten ganz über einander und das äusserst weiche Thier erscheint ganz platt. Man beobachtet aber leicht seine vierkantige Gestalt, während es frei schwimmt. Dabei bedient es sich der Lamellen als Flossen. Auch bei ihm sind die stabförmigen Körperchen im Vorderende sehr angehäuft. Die Augen scheinen zwar vorzugsweise dreikantig zu sein, doch finden sich mannigfache Unregelmässigkeiten. Einmal war das Pigment zwischen dem Parenchym geweihartig verzweigt (Fig. 8c).

Die Streifen, welche dem Munde das schattirte, rosettenförmige Aussehen geben, erweisen sich bei näherer Betrachtung als hohle Scheiden, angefüllt mit einer feinkörnigen Flüssigkeit, welche beim Zerdrücken, aber auch nur dann, ausläuft. Diese Scheiden setzen sich über den Mund hinaus fort in feinere Kanäle, die sich nach allen Seiten weit in den Körper hinein erstrecken, in einer blasigen Anschwellung enden und gleichfalls mit der granulösen Flüssigkeit erfüllt sind (Fig. $\mathbf{8}^{\mathrm{b}}$ ). Ich habe nie, we- 
der an der stärkeren Scheide im Munde, noch an den mit ihnen communicirenden Kanälen Contractionen bemerkt, kann sie also nicht für Muskeln halten. Zwischen ihnen aber sieht man die eigentlichen Radialmuskeln und Sphincteren. Welche Bedeutung der ganze abgebildete Stern hat, mögen spätere Forschter entscheiden. Fr ist bei dieser Species am meisten ausgebildet, weniger bei Hes. rostratum. Bei anderen fehlt er ganz, so bei Mes. Eltrenbergii. Vom Respirationssystem habe ich vier Hauptgelässe verfolgt, den vier Kanten entsprechend. Die Oefrnung $(e)$ ist die gewöhnliche über dem Munde; von hier gehen zwei Kanäle senkrecht nach den Seiten, wo sie sich in zwei nach vorn und hinten verlaufende Aeste theilen. Die hinteren Aeste biegen nach unten und vorn, ohne sich zu vereinigen, im Vorderende aber stossen alle vier Kanäle zusammen. Die feineren Gefiasse sind mir unbekannt, auch scheinen Abweichungen in der Anorchung der Stämme vorzukommen.

Auch die Geschlechtsorgane sind abweichend gebaut; indess sind meine Beobachtungen darüber nur fragmentarisch, wie gross auch die Anzahl der untersuchten Individuen ist. Der Hoden ist ein grosser hufẹisenförmiger Schlauch, der mit einer jener sehr leicht zu findenden, aber schwer zu deutenden Blasen in Verbindung steht. Am 31 . März waren noch keine hartschaligen Eier entrickelt. Diese zeigten sich aber schon zu Anfang April und ihre Zahl steigerte sich bis zum Juli; es werden zwanzig bis dreissig, in zwei oder vier Reihen sich schichtend. Sie sind, wie bei den meisten der übrigen Mesostomeen, nicht kugelrund, sondern abgeplattet, in der Mitte eingedrückt 


\section{8}

und dünner als am Rande. Diese biconcaven oder planconcaven Eier gehören gewiss zu den merkwürdigsten Formen, wohl mit besonderen Entwickelungserscheinungen verbunden. Die Beobachtung wird leider durch die undurchsichtige Schale verhindert.

Mes. tetragomum hält sich in klaren bewachsenen Teichen auf, die durch Ueberschwemmungen ihr Wasser bekommen. Bald kriecht es munter zwischen und an den Stengeln, bald durchschneidet es leicht das Wasser. In seiner Gesellschaft befand sich Hypostomum viride, doch ist es nicht so gesellig wie dieses.

M. Ehrenbergii, Oersd. Taf. IV. Fig. 9.

Planaria Ehrenbergii Focke (ex parte) [Annal. des Wiener BInseums. [.] ${ }^{*}$ ).

Obgleich Focke eine ganze Reihe rerschiedener Thiere zu Ifesostomum Ehrenbergii ziehen zu müssen meint, die durch eine Art von Generationswechsel in einander übergehen sollen, so sind seine speciellen Beobachtungen doch zum grössten Theil an der einen Form gemacht, welche er die platte nennt. Es ist dies unsere Figur 9, wobei ich aber bemerken will, dass durch ein Versehen von meiner Seite, da mir kein Hülfsapparat beim Zeichnen der sehr unruhigen Thiere zu Gebote stand, der

*) Herr Dr. Focke in Bremen hatie die Güte, auf meine Bitto um die betreffende, in Jena und IVeimar nicht aufutreibende Abhandlung, mir nicht nur dicse, sondern anch scine Originalzeichnungen dazu und einige spätere Beobachtungen ïber Mes. Ehrenbergii auf das Bereitwilligste mitzutheilen. Unsere Ansichten weichen freilich sehr von einander ab. 
Mund sammt der Wassergefässöffrung etwas zu weit nach hinten gesetzt worden ist. Auch habe ich nicht mehr als zwei Exemplare zu beobachten Gelegenheit gehabt, und so habe ich mich durch Autopsie nur mit dem äusseren Habitus und den inneren Verbältnissen, so weit sie abgebildet sind, bekannt machen können; dagegen kann ich über Anordnung und Deutung der Geschlechtsorgane nur nach der Analogie mit den übrigen Arten urtheilen, indem nur die Dotterstöcke in ihren ersten Anfüngen entwickelt waren.

Dieser Strudelwurm ist so durchsichtig, dass man Mühe hat, obgleich er an Grösse alle mir bekannten Rhabdocoelen übertrifit, ihn im Wasser zu erkennen. Das Vorderende ist abgerundet, rüsselförmig verlängert, das Hintertheil zugespitzt. Der Körper ist sehr platt. In das sonst ganz wasserklare Parenchym ist mitunter ein gelbes Pigment eingestreut, das aber der Durchsichtigkeit keinen Eintrag thut. Nur der Darm, gleich hinter den Augen beginnend, und sich bis in den Schwanz erstreckend, macht sich schon dem unbewaffneten Auge als ein dunkler Streifen bemerklich. Meine Meinung über die ron Focke sogenannten Muskeln, die, neben dem vorderen Theile des. Darmes entspringend, sich an den Augen vorbei bis an das Vorderende erstrecken $(y)$, wo sie sich etwas ausbreiten und convergiren, habe ich schon ausgesprochen. Die einzelnen geschlängelten Fäden gehen von grossen länglichen Zellen aus $(g)$, welche eine eigene Schicht um den Darm bilden. Vor den Augen schliessen sie einen dreieckigen, besonders durchsichtigen Raum ein, der von einem feinen, hier und da Anschwellungen zeigenden Fadennetze erfüllt ist. Auch 
den ganzen übrigen Körper fand ich mit solchen feinen $\mathrm{F} \ddot{\mathrm{a}}$ den durchzogen $(f)$, die oft in die stabförmigen Körper überzugehen schienen und zwischen denen nur sparsam Zellen, einen Kern enthaltend, sich zeigten. Ich halte es von grosser Wichtigkeit, über die Histologie der Rhabdocoelen näheren Aufschluss zu bekommen, weil in inr ganz eigenthümliche Elemente verborgen zu sein scheinen.

Die drüsigen Gebilde zu beiden Seiten des Darmcanals, von denen Focke glaubt, dass sie mit den Digestionsorganen in Verbindung ständen, sind die Dotterstöcke (vii), worüber wohl jetzt, nach den vorlsergehenden Darstellungen, kein Zweifel sein kann. Die Ausführungsgänge, welche F o ck e beobachtet, sind gewiss die von mir in Fig. 6a. $d v$ beschriebenen. Als Hoden beschreibt Focke zu jeder Seite ein drüsiges Organ „,neben dem Saugnapfe beginnend und bis über die Jetzten Drüsen- (Dotter) Haufen hinausragend, das nach innen einen mehr geraden Rand hat, nach aussen aber in viele unregelmässige Läppchen und Fortsätze zerschlitzt ist." Von den Hoden führen einige vasa deferentia nach den mit unserer Fig. 6a. $v z^{\prime}$ und $v z^{\prime \prime}$ übereinstimmenden Blasen. In der citirten Abhandlung erwähnt Focke nicht, dass er in den Hoden oder deren Ausfuilrungsgängen Zoospernien gefunden. Er hat diese aber später beobachtêt, wie ich es aus den Nachträgen in seinen Originalzeichnungen sehe. Auch die äussere Geschlechtsöffnung, die ihm in der Abhandlung noch unbekinnt, fand er nachher hinter dem Munde. Der sogenannte Penis kann aus ihr natürlich nicht hervortreten, eben so wenig, wie sich O e rsted's Vermuthung, dass sich am Grunde des cylindrischen Theiles dieses Organs wahrscheinlich eine Oeff- 
nung für Samen finde, bestätigt. Ob die langen Oviductus, welche Fock e beschreibt, eigene Wandungen haben, kann ich nicht entscheiden; von meinen Beobachtungen spricht nur die eine, bei Mes. rostratum angeführte, dafür.

F ock e unterscheidet drei Formen seiner Planaria $\mathbf{E} h$ renbergii, eine platte, eine vierkantige und cine runde.

Von den in der Zool. Dar. beschriebenen Planarien rechnet er nun

a) zur platten Form

Plan. grossa, rostrata, Lingua, strigata,

b) zur vierkantigen

Plan. tetragona,

c) zur runden

Plan. linearis.

ob $\mathrm{Pl}$ grossa und strigata eigene Species sind, weiss ich nicht. Ich glaube es aber. Dass $\boldsymbol{P l}$. rostrata, unser Mes. rostratum, eine wohlbegründete Species ist, dafür sprach sich schon $\mathrm{O}$ erst ed aus. Ist mein Mes. Lingua die Müller'sche Plan. Lingua, so ist auch diese total von Mes. Ehrrenbergii verschieden, wie sich aus meiner Beschreibung ergiebt. Da Focke ferner im Herbste nicht mehr das eigentliche Mes. Ehrenbergï, sondern Mes. tetragonum fand, ohne aber das Auskriechen des letzteren aus den Eiern jenes zu beobachten, so glaubte er, das platte Mes. Ehrb. lege Eier, aus denen im Herbste die vierkantige Form hervorkäme. Auch dies wird durch meine Beobachtungen widerlegt. Eben so selbständig scheint die runde Form Plan. linearis zu sein.

Von allen den Müller'schen Planarien stimmt nur die 


\section{1}

auf Taf. 106 als Varietät von Plan. tetragona abgebildete mit Mesost. Ekrenbergii überein.

M. personatum Nobis. 'Taf. IV. 10-10c.

Dieser ausgezeichneten Art, die ich im Juni in grosser Menge beobachten konnte, nachdem ich sie einzeln schon vom Beginn des Frühlings an verfolgt hatte, habe ich ihren Namen von dem maskenartigen Aussehen des Kopfes gegeben.

Der vorn abgerundete, nach hinten allmählig zugespitzte Körper ist bei dem schon längere Zeit ausgekrochenen Thiere vom Schwanze bis zu den Augen durch eine doppelte Pigmentschicht, eine kaffeebraune und eine rein schwarze, intensiv dunkel gefärbt, nur die Bauchseite schillert ins Grau. Am Kopfe verliert sich das schwarze Pigment, und vor den Augen sind auch zwei Flecke, wo das braune fast ganz fehlt, so dass zwei durchscheinende Stellen, wie ein Paar grosse Augen, erscheinen. Diese verschiedene Zeichnung des Körpers ist bei den grösseren Thieren schon mit unbewaflnetem Auge sehr gut zu bemerken.

Die eigentlichen Augenflecke, die man bei den jungen Individuen ganz deutlich sieht $\left(10^{\mathrm{b}}\right)$, sind bei den ältern in dem Pigment verborgen, fehlen aber nicht, wie es bei oberflächlicher Betrachtung den Anschein hat. Ausser der Oeffnung des Wassergefässsystems über dem Munde (10 a $e$ und $\left.10^{b} e\right)$ ist noch eine zweite im Nacken vorhanden $\left(e^{\prime}\right)$, die bei den Jungen sich leicht als ein weisser Punkt bemerklich macht.

Den eben ausgekrochenen Jungen fehit das schwarze 
Pigment und das braune ist glcichmässig durch den ganzen Körper verbreitet. Der Embryo ist, noch elhe Augenflecke und Mund zu sehen, mit dem Flimmerepithelium über\%ogen; die Gefäissstämme mit ihren Mündungen zeigen sich, nachdem der Nund sich geöffinet, jedoch noch keine deutlichen Unrisse hat.

\section{M. pusillum Nobis. Taf. V. 11.}

Dass dieses winzige und zierliche Würmchen eine gute Species ist, und nicht etwa ein nicht ausgewachsenes Junges einer der vorigen Arten, zeigt die Lage der Wassergefässöfnung, ziemlich weit vor dem Munde $(e)$. Es ist blassgrün oder blassgelb. Mund und Gefässstämme scheinen imner sehr deutlich durch. Von Geschlechtsorganen konnte ich nichts beobachten. Gefunden wurde das Thierchen am 7. Mai und früher.

\section{Gattung: Typhloplana O ers do ex parte.}

Mund in der Mitte der Bauchseite. Keine Augen. Wie schon oben erwähnt, führt Oersted eine Typlloplana marina auf, deren Mund hinter der Mitte des Hörpers liegt; die Beschreibung ist aber, da er nur ein einziges Exemplar beobachten konnte, zu dürftig, um über die Stellung dieser Turbellarie urtheilen zu können。

\section{T. viridata Nobis. Taf. V. 12. 12 a \\ Planaria viridata Zool. Dau.? \\ Typhloplana variabilis $O$ ersd. ex parte?}

Bei Typhloplana variabilis citirt $O$ ersted eine ganze Reihe von Synonymen. Ich bin desshalb zweifelhaft, ob die T. viridata zur $\mathbf{O}$ ersted'schen variabilis gezogen wer- 
den könne; die unsrige ist nichts weniger als variabel. In der länglichen, gleichmässig nach beiden Enden zugespit\%ten Körperform, in den grasgrünen, durch grosse grüne Kügelchen hervorgerufenen Farbe, in der Lage der Wassergerässöffnung vor dem Munde habe ich bei zablreichen von mir beobachteten Exemplaren nie eine Abweichung gefunden. Um über jene Synonymen zu entscheiden, wird man sein Hauptaugenmerk auch auf die Lage der Gefäss. öfnung zu richten haben. Typhloplana viridala stimmt in dieser Hinsicht ganz mit Mesostomum pusillum überein (vergl. Fig. 12a).

Die Eier sind elliptisch, roth; im März und April waren die Eier noch nicht zu finden, sie zeigten sich aber in den ersten Tagen des Mai. Die Dotterstöcke scheinen gewöhnlich als zwei längliche donklere Schlüuche durch.

T'. sulphurea Nobis. Taf. V. 13. 13 a.

Sie ist von schwefelgelber Farbe, grün und rolh getiipfelt, an beiden Enden abgerundet. Die beiden seitlichen Wassergefässstämme vereinigen sich nicht, wie bei den übrigen Mesostomeen, in einer gemeinsamen Oeffnung, sondern mïnden gesondert $\left(13 \mathrm{a}_{0} e\right)$. Die Mündungen liegen aber, wie bei den beiden vorhergehenden Arten, zwischen dem Munde und dem Vorderende. Beobachtet zuerst am 31. März. Von Geschlechtsorganen wurden nur die Dotterstöcke erkanut. 


\section{Schisostomeae.}

\section{Gattung: Thacrostomum.}

Die Mundöffnung erscheint als eine Längsspalte, hinter den zwei kleinen, einander genäherten Augen, im vorderen Drittel des Körpers.

\section{M. hystrix Oersd. Taf. V. 15.}

Turbeila platurus Ehrbg.

Die bei dieser Art immer sehr entwickelten Stäbchen, von denen je zwei oder drei an ihrer Basis zusammengewachsen sind, geben dem länglichen, hinten fast gerade abgestutzten Körper ein stacheliges Aussehen. Sehr oft ist er auch mit längeren Borsten besetzt. Charakteristisch ist der platte Schwanz, dessen sich das Thier beim Kriechen zum Aufstemmen und Fortschieben bedient. Dass der am Hinterleibe befindliche gekrümmte Haken $(b)$ das Zeugungsglied sei, wie Oersted behauptet, ist nir sebr unwahrscheinlich, besonders da dieser Naturforscher andere Geschlechtsorgane von MI. hystrix gar nicht kennt. Mir scheint dieser Haken eher ein Haftorgan zu sein. Am 28. Juni hatte ein Individuum zwei längliche Eier. ohne harte Schale.

\section{Gattung: Sclhigastomum Nobis.}

Die Mundöllinung ist eine Längsspalte ím Vorderende; hinter der Spalte die Augen.

Scli. productum Nobis. 'Taf. VI. 16. 16a.

Der schlanke, nach beiden Enden allmählig zugespitzte Körper ist von bräunlicher oder gelbbrauner Farbe; das 
Gelb tritt besonders bei jüngeren Individuen mehr hervor. Es könnte zweifelhaft erscheinen, ob die vor den Augen liegende Spalte wirklich der Mund sei, da sich noch vor der Mitte des Leibes ein zweites Organ $\left(o^{\circ}\right)$ findet, das mit dem Munde der Mesostomeen die grösste Aehnlichkeit hat, und die vordere Spalte an eine bei Mesostomum Ehrenbergii beschriebene Bildung erinnert. Sie erinnert aber auch nur daran, denn es ist nicht, wie dort, ein blos durchsichtiger Raum, begränzt von den gescllïngelten, mit Muskeln verwechselten Fäden, sondern es ist eine wahre Oefinung mit sehr bestimmt hervortretenden Rändern. Ist meine Deutung die richtige, so ist $o^{\prime}$ derselbe Saugmund, den wir bei Prosiome lineare kennen gelernt. Gleich hinter ihm liegen die Generationsorgane. Der sogenannte Penis, der bei den Mesostomeen besprochen wurde, findet sich hier nicht, woht aber ein einfacher Keimstock, ein Beweis mehr für meine Behauptung, dass wir es auch dort gar nicht mit einem männlichen Organ zu thun.

Die Dotterstöcke sind gewöhulich einzelne Zellenhaufen, in bekannter Lage. Wie wenig sie aber an bestimmte Formen gebunden sind, kaun man aus Fig. 16a sehen, wo der in dem allgemeinen Theile beriihrte Fall eingetreten ist: die die einzelnen Zellenhaufen umgebenden Membranen sind, indem sie an einander stiessen, resorbirt; es sind zwei lange seitliche Dottersäcke entstanden, ja sogar eine quere Verbindung zwischen ihnen auf diese Weise herbeigelührt.

Diese Art wurde in mrosser Menge von Anfang Mai bis zum 27. gefunden in kleinen Regen-Pfützen. Wenige Tage darauf war das Wasser vollständig verdunstet. Ain 
2i. Juni weichte ich ein Stückchen des trocknen Erdbodens anf und er war fast ganz bedeckt mit Eiern der Turbellarie und mehrerer Entomostraceen. Als es bald regnete, waren auch binnen wenigen Tagen die Pfützen wieder mit ihren früheren Bewohnern bevölkert, ohne dass sich mir in den vorher untersuchten Eiern eine Spur von beginnender Entwichlung des Embryo gezeigt hätte.

\section{Microstomeae.}

Gattung: Thicrostomman O ersd.

Das Darmrohr erstreckt sich blindsackartig äber die Mundöffnung in das Yorderende. Zwei Augen.

\section{M. lineare Oersd. 'Taf. VI. 17. 1;b.}

Planaria linearis Zool. Dan.

Körper vorn abgerundet. Nahe am Vorderence und am Rande zwei rothbraune Augenflecke, dahintei, an der Unterseite, der Mund, ron unten oder oben gesehen als eine Längsspalte, ron der Seite in Trichterform erscheinend. Körperfarbe gelblich, an den Seiten heller. Der Darm schcint als ein dunkleres, hie und da ausgezacktes Band durch. Das äussere Flimmerepitheliun ist stärker entrickelt, als bei den meisten der übrigen Familien. In der Oberlaut finden sich in grosser Anzalal jene Giftorgane (1 b $^{3}$ eingebettet, welche man durch Ehrenberg zuerst bei den Hydren kenuen lernte. Aus einer flaschenförmigen, nur lose mit dem Körperparenchym verbundenen Blase können vernittelst eines elastischen Stieles drei Widerhaken und ein aus deren Vereinigungspunkte entspringen- 
der, langer, klebriger Faden entfaltet werden. Wenn die Haken eingezogen sind, so legen sie sich zu einer einzigen Spitze zusammen, wie in 17b links dargestellt. Microstomum lineare bemächtigt sich oft grösserer Naiden, Daphnien u. a., um die es sich wie eine Schlange schlingt.

Dass das Darmrohr über die Mundöffnung hinwegragt, sieht man am besten bei der Seitenlage des Thieres. Der Darmkanal verliuft fast gleich stark bis zur Afteröffnung, an vier bis fünf Stellen aber erweitert er sich bis an die Oberhaut. Es spricht sich hierin eine Tendenz zur Gliederung aus, was auch dadurch bestätigt wird, dass immer gleich hinter einer solchen Erweiterung die Quertheilung vor sich geht. Bei dieser Quertheilung scheinen ganz die physiologischen Vorgänge statt zı haben, wie bei den Naiden, wie denn überhaupt die Strudelwürmer in den Microstomeen sich aufs Engste an jene Würmer, namentlich die Gattung Aeolosoma, anschliessen. Die ersten Andeutungen, dass die Theilung beginnen soll, werden durch das kaum merkliche Auftreten der Augenflecke gegeben. Ich habe schon oben darauf hingewiesen, dass auch am Embryo in $\mathrm{Ei}$ am ersten sich die Augenflecke zeigen. Hier ist ganz dasselbe Verlältniss, und wir schliessen daraus ganz folgerichtig, dass die Rolle der Augenflecke keine so untergeordnete sein könne, oder rielmehr, dass in ihnen sich das Vorhandensein eines Nervensystems zeigt. Das neue Individum, sofern es nicht mehr integrirender Theil des Mutterthieres ist, wird zunächst charakterisirt durch das Hervortreten eines separaten Nervensystems. Das zweite sich bildende Organ ist der Mund mit der Schlundröhre. Bei der jungen Naide ist der künftige Mund zuerst 
eine ganz geschlossene Höhle, ausgekleidet mit Flimmerepithelium; dann öffnet sich diese Höhle nach aussen und zuletzt stellt sich die Verbindung mit dem Darm her. Wahrscheinlich verhält es sich auch bei den Microstomeen so. Es tritt dann ein Stadium ein, wo bei dem neugebildeten, noch nicht abgetrennten 'Thiere der Darm durch Schlund und Mund mit der Aussenwelt zwar communiciren kann, seine Nahrung aber noch durch das Mutterthier empfängt. Die Theilung selbst wird durch eine Verdichtung oder Verdickung der Gewebe hervorgebracht. Die Darmwände werden so stark, dass die Höhlung auf ein Viertel bis auf ein Fünftel des normalen Durchmessers reducirt ist.

Beiläufig sei noch bemerkt, dass schon in der Zool. Dan. der Quertheilung gedaclit wird: „corpus in medio coarctatum, quasi ex duobus compositum.

Gefässe sind nicht beobachtet, wohl aber scheinen die zwischen Augen und Mund, aber noch etwas höher als erstere gelegenen Grübchen den oft erwähnten Stigmen zu entsprechen. Sie liegen in einem Haufen gestielter Zellen.

Ueber die Zeugungsorgane, die sich höchst wahrscheinlich periodisch entwickeln, giebt $O$ ersted eine sehr fragmentarische Notiz. „Das Zeugungsglied, heisșt es, ist unten kugelförmig und endigt sich in einer langen, dünnen, harten und gewundenen Spitze." Wenn nichts Anderes, so entnehmen wir doch aus dieser Beobachtung, dass, gleichfalls wie die Naiden, auch die Microstomeen von Zeit zu Zeit Organe haben, die ihnen sonst fehlen, Geschlechtsorgane. Ich meine daher, dass sich v. Siebold's Frage (vergl. Anat. S. 161), „ob die kleinen geschlechtslosen?! Strudelwürmer, z. B. Derostomum, Microstomum u. a., 
wirklich selbständige Gattungen und nicht etwa die Larven von andern niederen Thieren sind" sich von selbst erledigt.

Gattung: Stenostomam $N$.

Der lange enge Oesophagus, über welchen hinweg der Darm sich nicht blicksackartig nach vorn erstreckt (man vergleiche die den Hauptfiguren beigefügten Seitenansichten), sowie der Mangel der Augenflecke und der Giftorgane machen die Trennung der beiden folgenden Arten von Microstomum als selbständige Gattung nothwendig.

St. leucops N. Taf. VI. 18.

Microstoma leucops Oersted?

Derostoma leucops Dujès?

Mit?v. Siebold halte ich Derostomum leucops $D u$ $j e ̀ s$ und Microstomum lineare Oersted nicht für dasselbe Thier, da jenes die röthlichen Augenflecke nicht hat, welche bei Microstomum lineare nie fehlen. Vielmelir glaube ich, Derostomum leucops Dujès zur vorliegenden Species ziehen zu müssen. Die Beschreibung, die Oersted von seinem Microstomum leucops giebt, stimmt fast ganz mit unserer Abbildung überein, nur habe ich mich nie von dem Vorhandensein der zusammengesetzten Augen, die „innerhalb des Pigmentes einen flachen durchsichtigen Körper mit zwei Reihen Punkte oder Vertiefungen (vielleicht eine Linse?)" haben sollen, überzeugen können. Es finden sich allerdings regelmässig' zwischen dem Munde 
und den Grübchen $l$ zwei, auch in unserer Figur angedeutete kleine Organe, die aber kein Pigment um sich haben und die ich nicht für Augen zu erklären wage.

In dem vorderen durchsichtigen Theile des Körpers bemerkt man leicht das geschlängelte Wassergefäss $(v, a)$.

Wie bei Microstomum lineare vermuthe ich, dass die zwei nahe am Vorderende gelegenen Grübehen $(l)$ Respirationsöffnungen sind, obgleich mir ihr Zusammenhang mit den Wassergefässen nicht klar geworden. Auch die folgende Species hat sie. Vom Vorderende ziemlich weit entfernt, in der Mitte der durchsichtigen Körperstrecke, liegt der Mund ( 0 ), der in einen verlialtnissmässig langen Schlund übergeht. Der Schlund ist nicht viel weiter als das Wassergefïss, womit man ihn leicht verweehseln kann. Der bräunliche Darm ist vom Schlunde selir bestimmt abgesetzt.

\section{St. unicolor N. Taf, VI. 18.}

Ist von St. leucops leicht zu unterscheiden an seiner schlankeren Körperform, an der über den Darm hinausreichenden ziemlich gleichmässig verbreiteten blassgrünen Farbe und dem dem Vorderende näher gerückten Munde. Es wurde im Mai und Juni zahlreich in einigen vereinzelten Wassergruben am Fusse eines Sandberges beobachtet, in denen sich Distomeen, namentlich Eutstrum, in ungeheurer Menge zu entwiekeln pflegen.

Indem ich diese Arbeit schliesse und der wohlwolfenden Beurtheilung der Naturkundigen äbergebe, hat 
sich mir die freudige $\Lambda$ ussicht eröfnet, im bevorstehenden Sommer an den isländischen Küsten zoologischen Studien obliegen zu können. Hoffentlich finde ich dort Gelegenheit zu ergänzenden Untersuchungen über den Bau und die Lebensweise der das Meer bewohnenden T'urbellarien. 


\section{Explicatio tabularum.}

\section{Tab. 䀚 *)。}

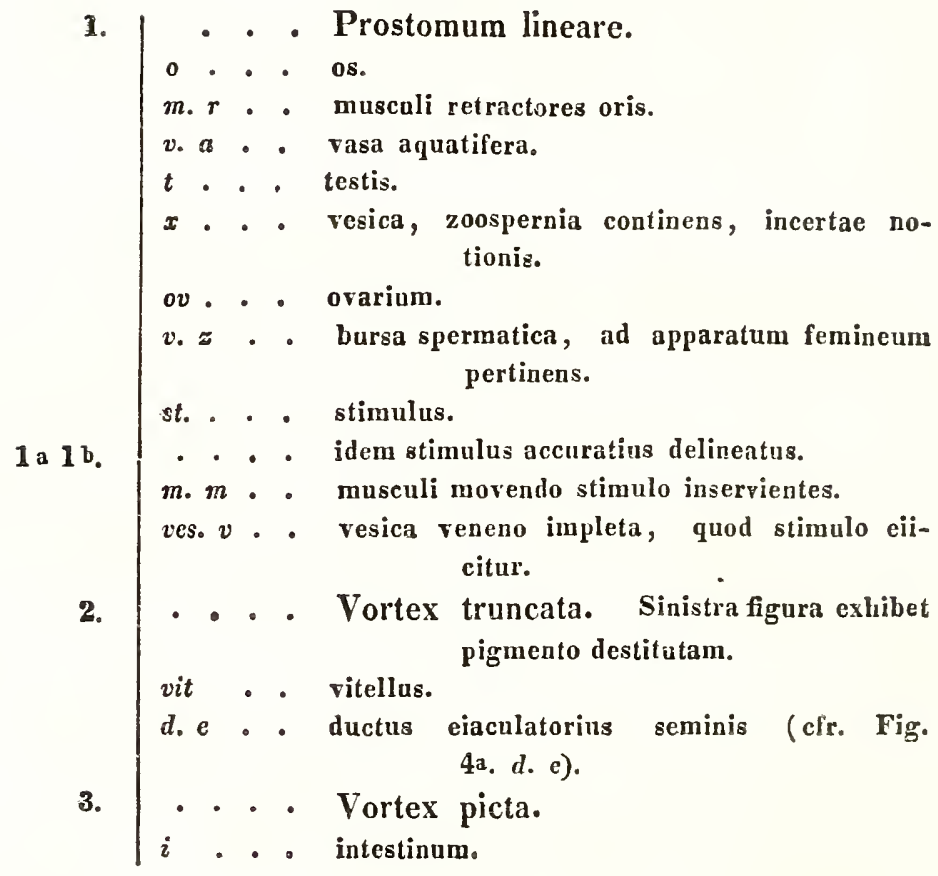

-) Litterae, quibus in diversis figuris eaedem res siguificantur, semel tantum explicari solent. 


\section{3}

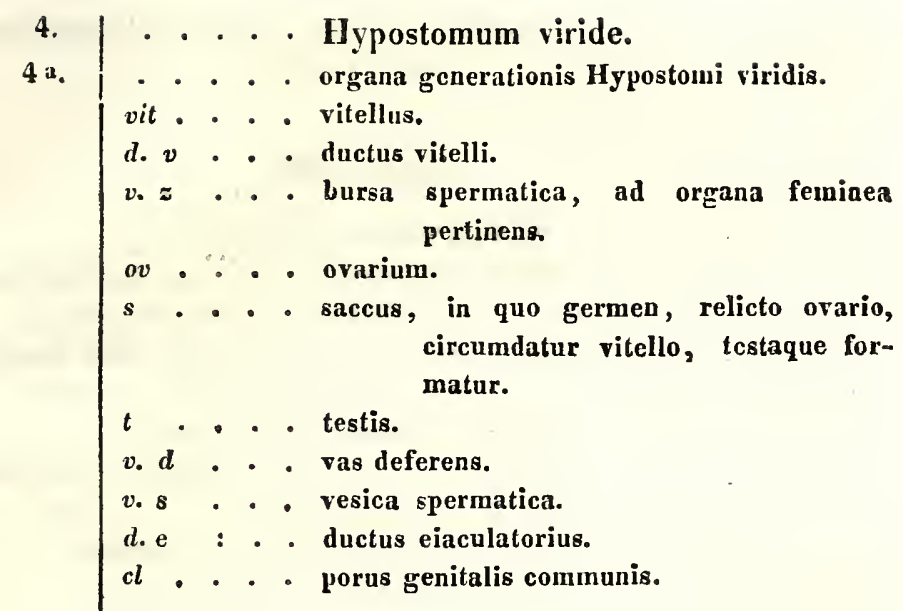

\section{Tab. $\mathbf{\text { II. }}$}

4 b. $\quad \begin{gathered}\text {. . . . os et intestinum Hypostomi viridis. } \\ p\end{gathered}$

m. $m$. . - musculi, quibus os suspenditur et retrahitur.

5. c . . . - cellulae glandularum speciem referentes.

5 a.

gen . . genitalia.

. . . haec figura exhibet situm vasorum aqua-

tiferorum Derostomi unipunctati.

5 b. . . . . organa generationis Derost. unip.

6. . . . Mesostomum Lingua.

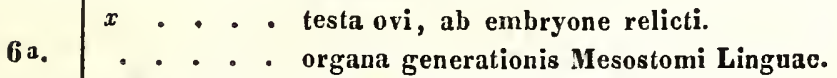

$v \cdot z^{\prime}-v \cdot z^{\prime \prime}$. vesicae, zoospernia continentes.

d. $v$. . ductus vitelli.

$t$. . . canalis.

$p \cdot g$. . porus genitalis.

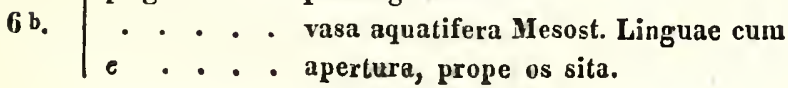




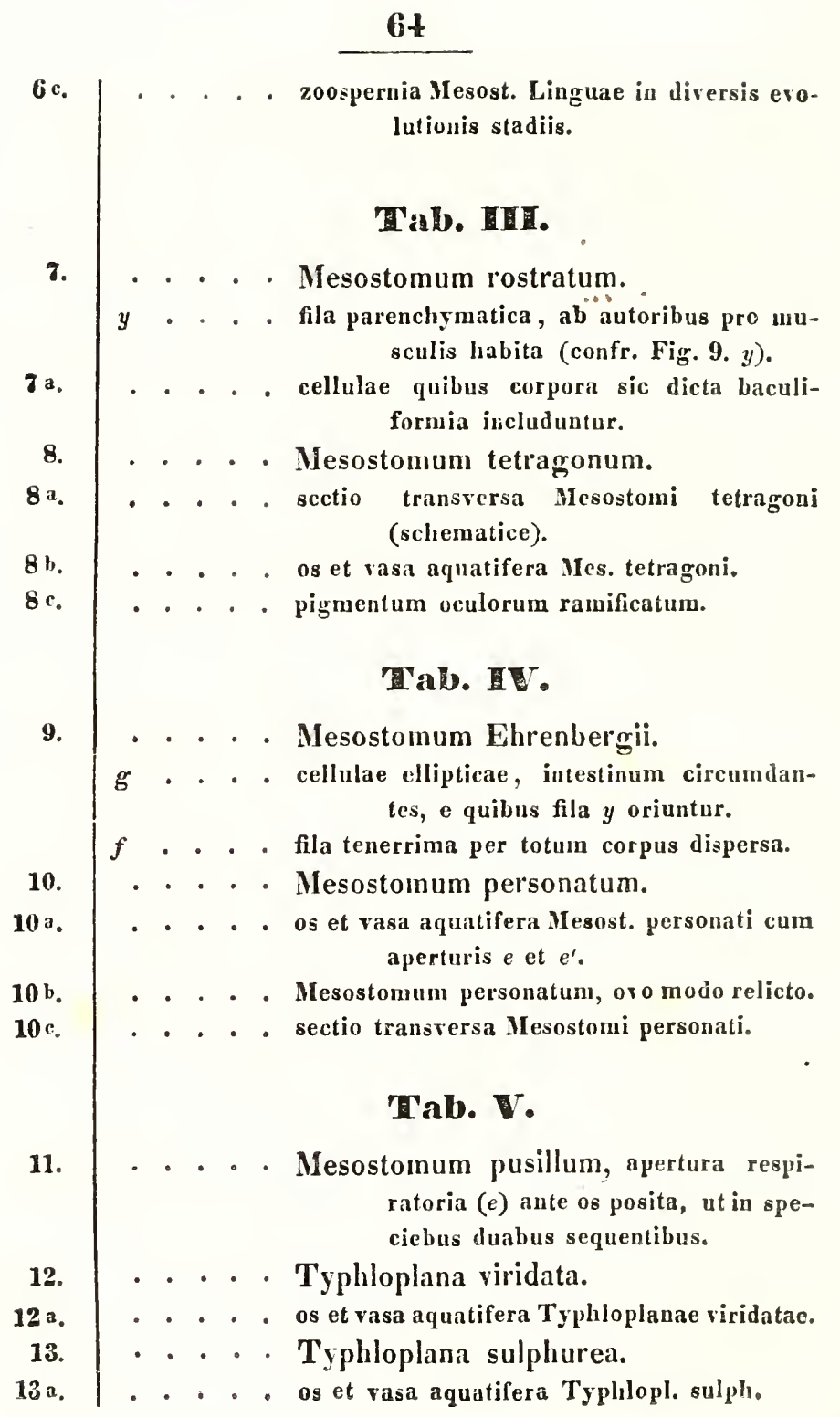




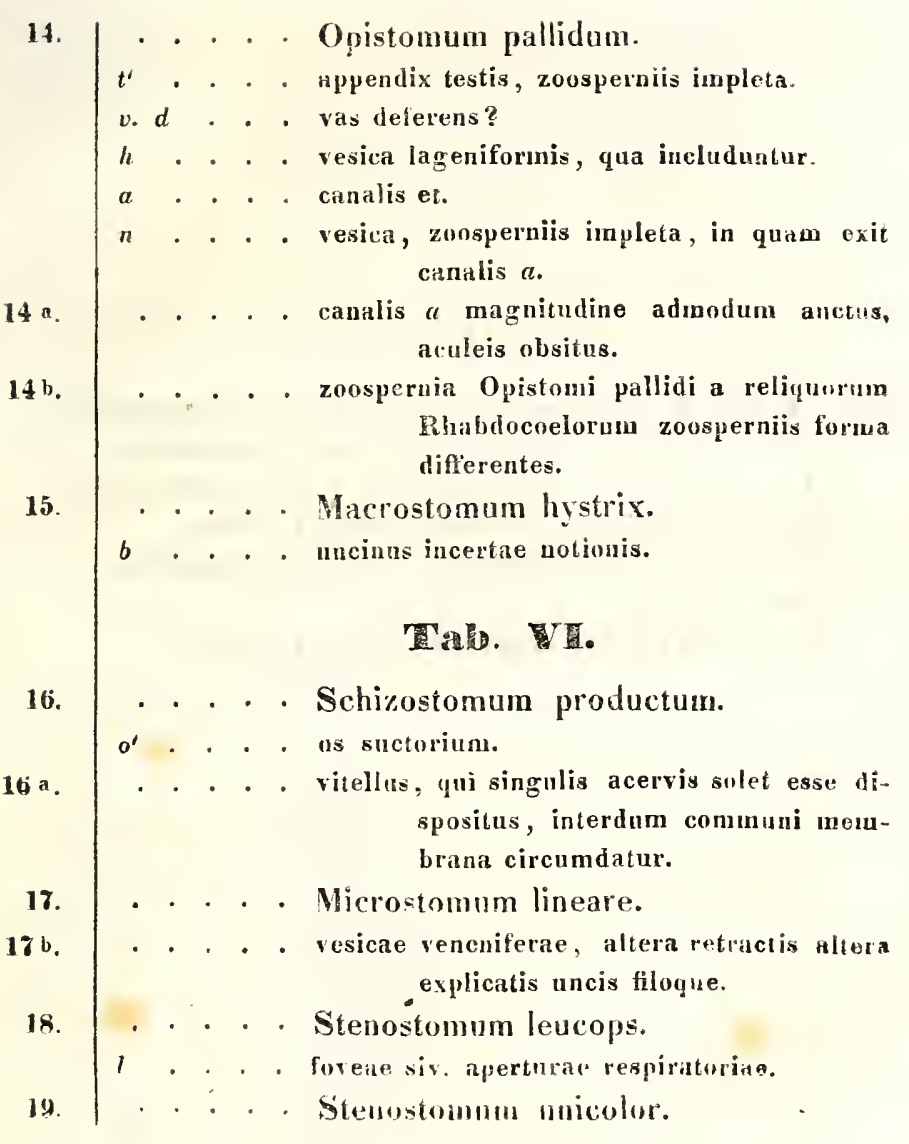




\section{Druckfeh I e r.}

Seite 3. Zeile 2 von unten liess Dendrocoeli statt Deudrocoeli.

- 3. - 9 v. u. I. Dendrocoelen statt Deudrocoelen.

- 11. - I v. u. liess Dendrocoelen statt Dendrocoelen.

- 23. - 8 v. n. 1. Prostomum statt Prostoma.

- 35. - 4 v. u. 1. Derostomum statt Derostomeum.

- 53. - 3 v. o. l. der statt den.

- 55. - 13 v. 0. 1. Prostomum statt Prostome. 
Taf.I.

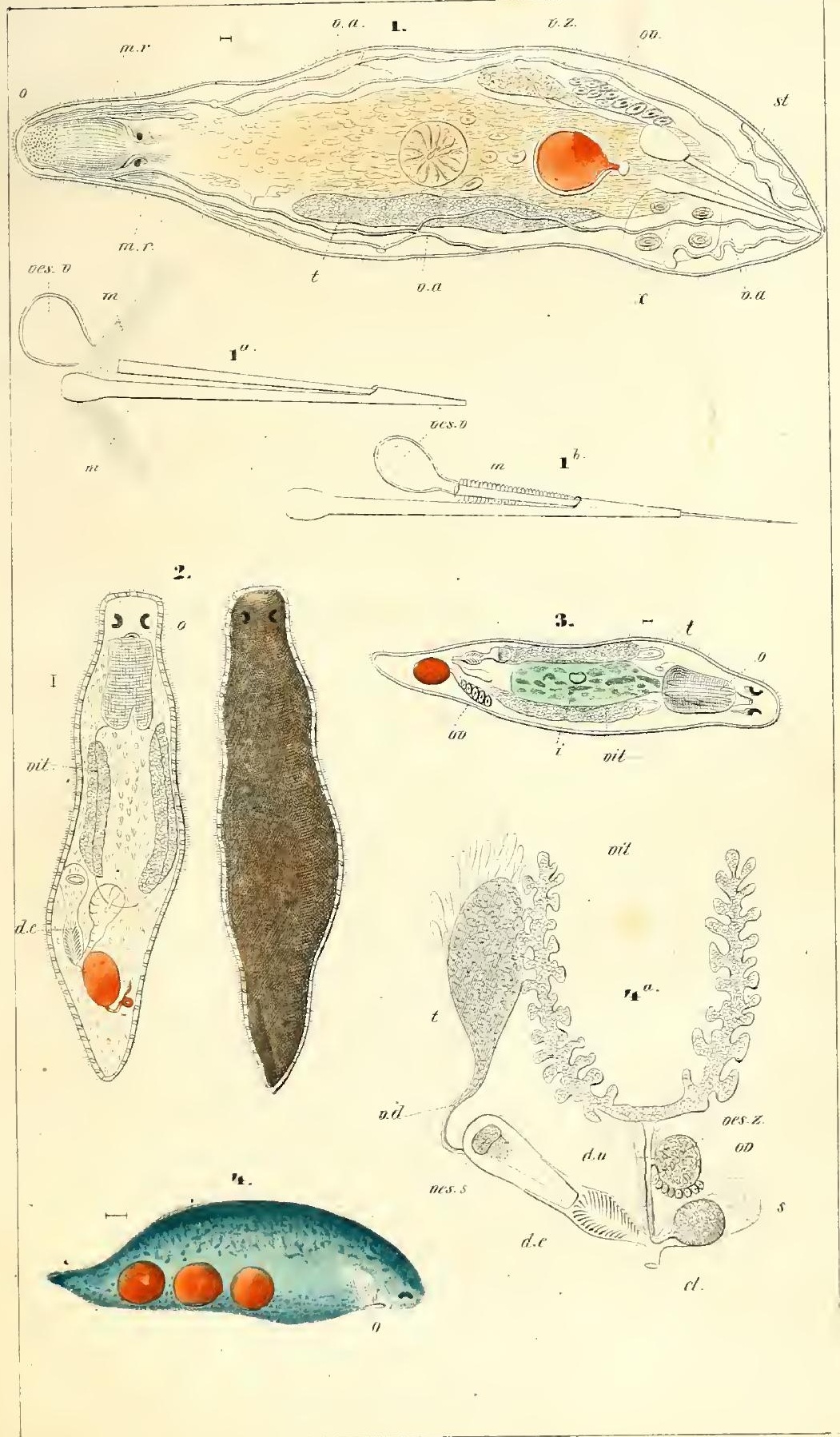





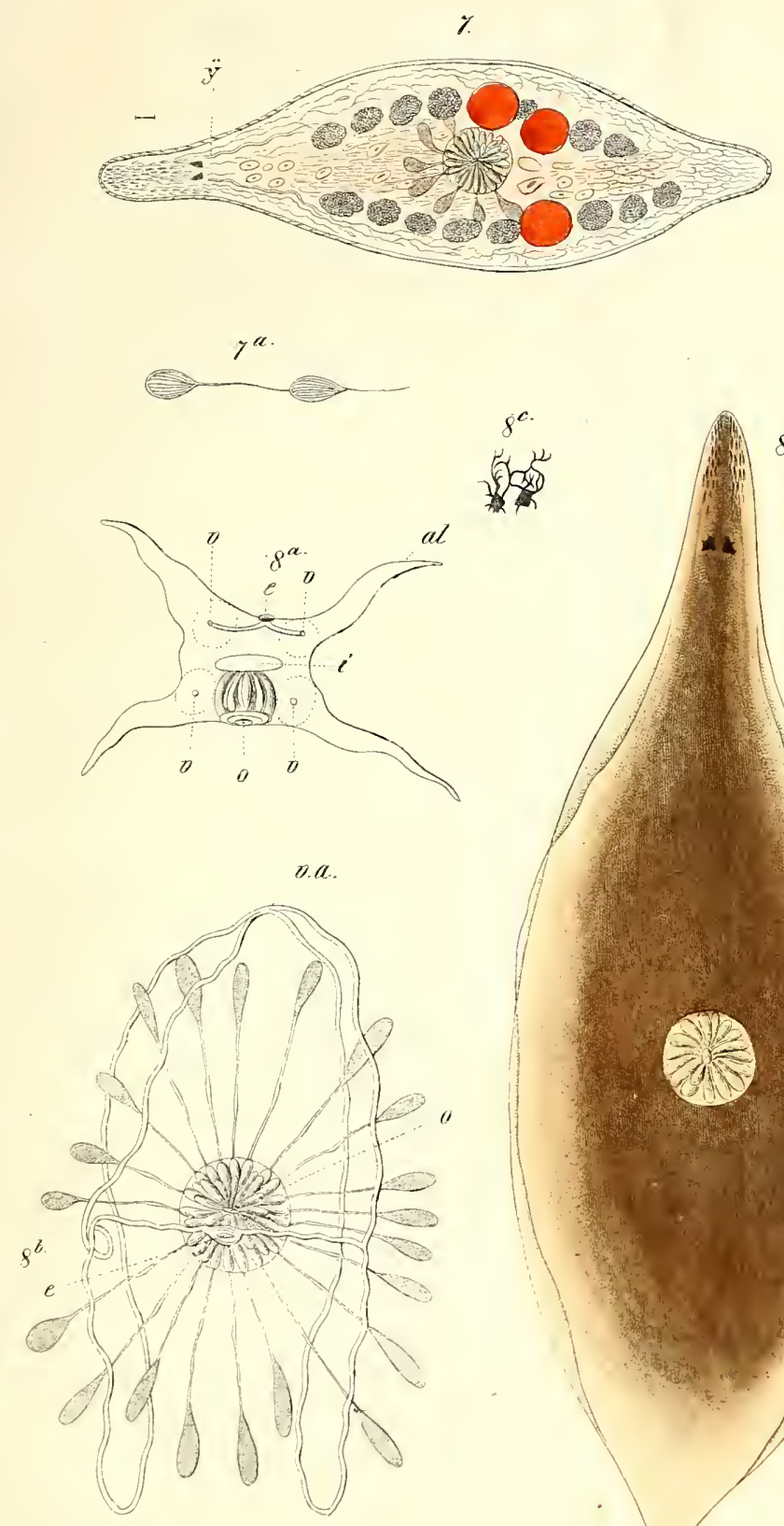

$\delta$.

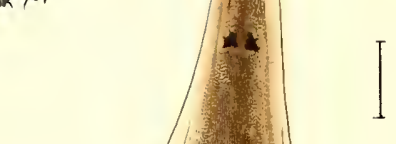



TuF:U.

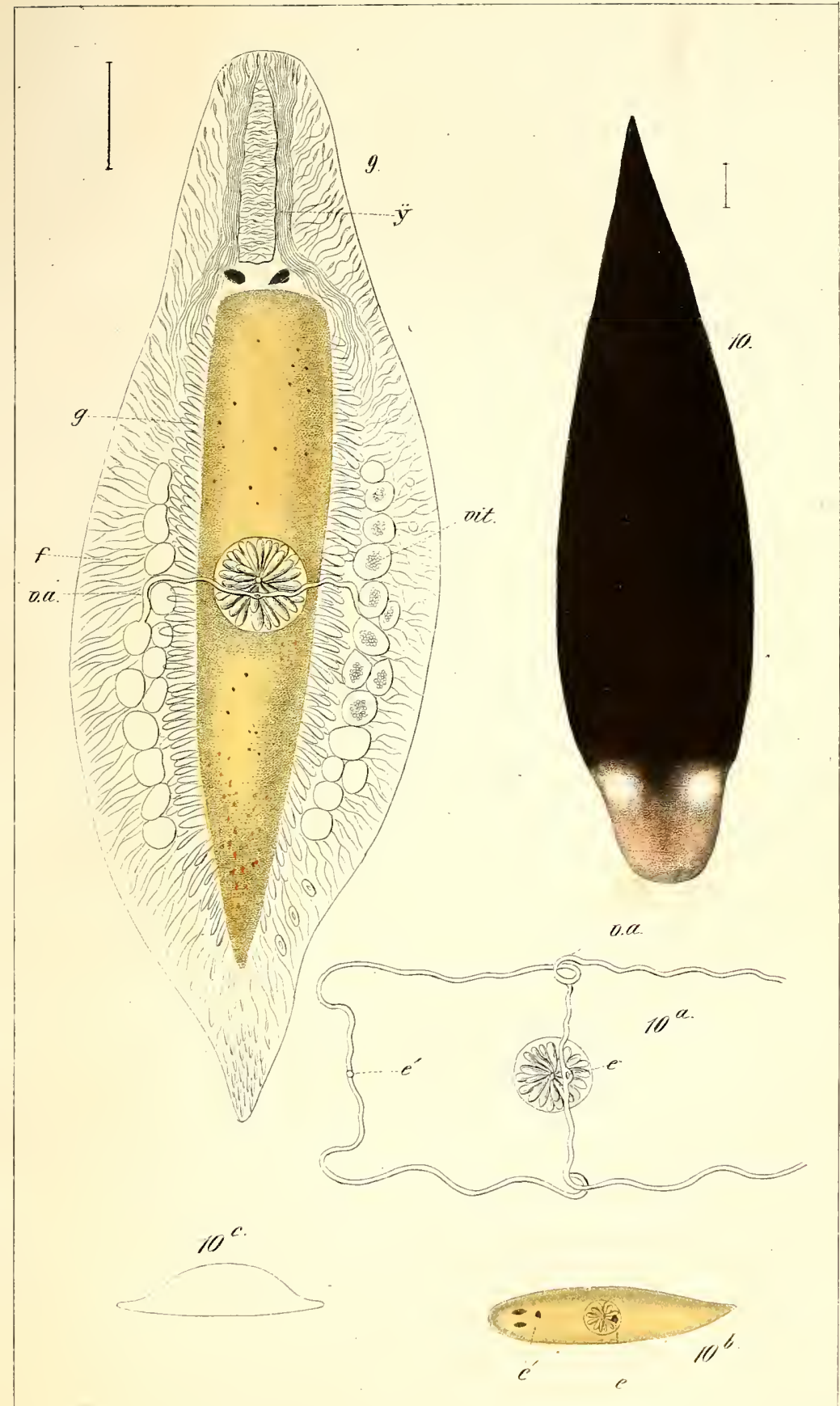





\section{Tat:}
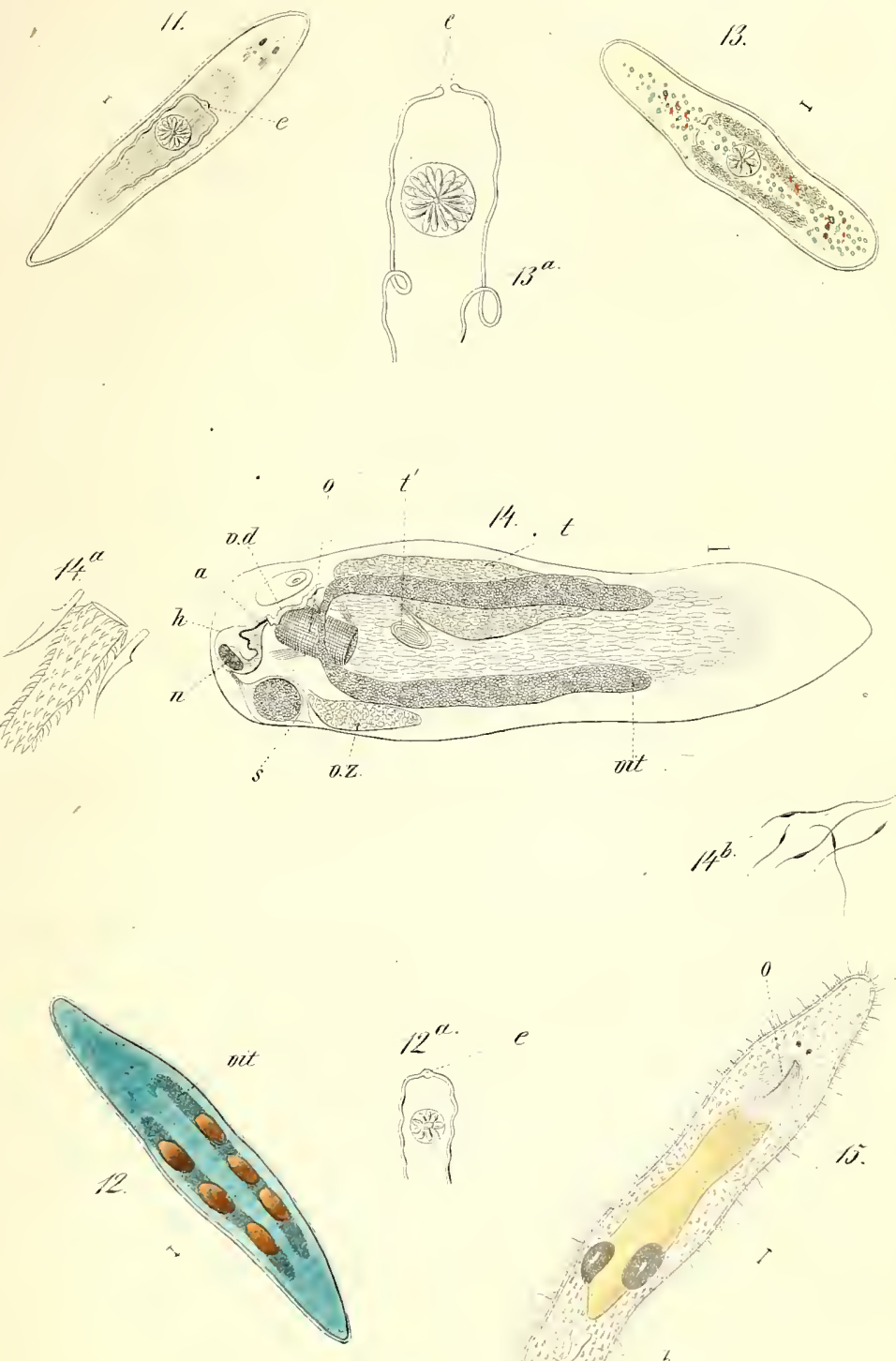




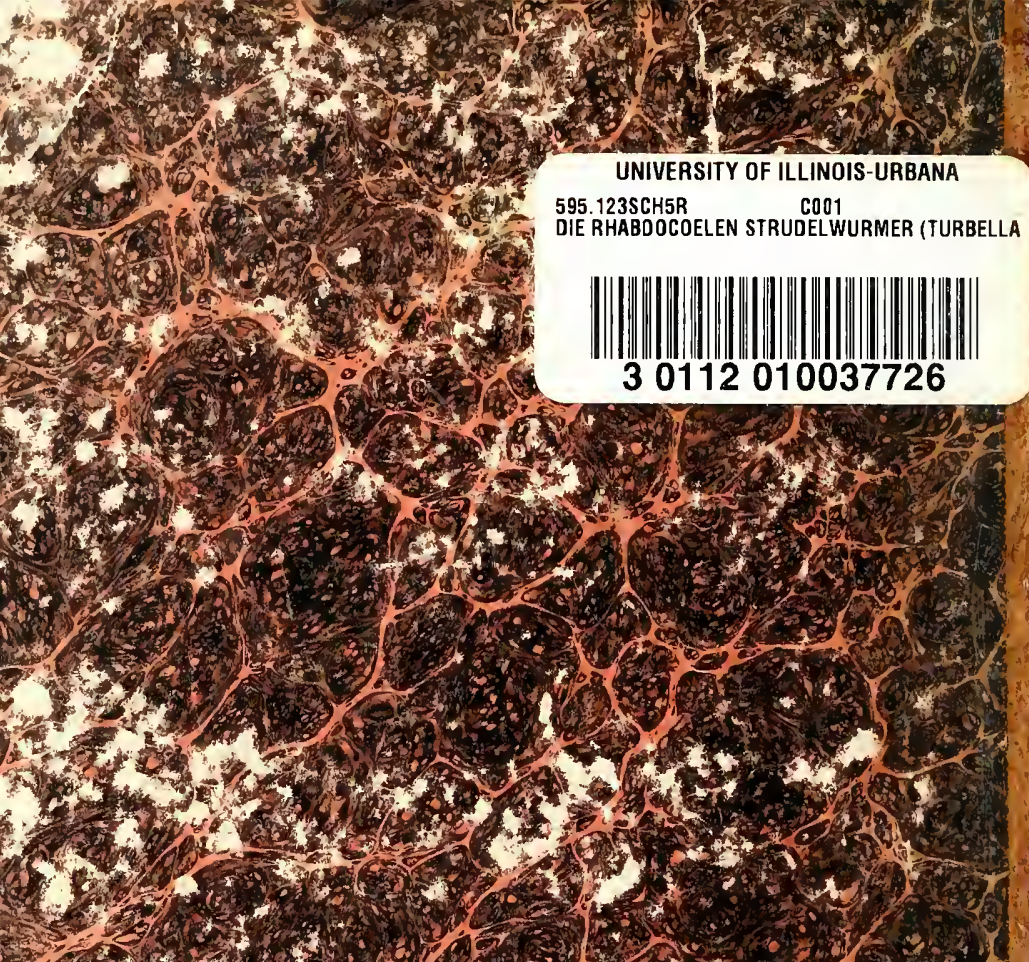

